\title{
Site-Specifically Labeled Immunoconjugates for Molecular Imaging-Part 1: Cysteine Residues and Glycans
}

\author{
Pierre Adumeau, ${ }^{1}$ Sai Kiran Sharma, ${ }^{2}$ Colleen Brent, ${ }^{1}$ Brian M. Zeglis $\odot^{1,2}$ \\ ${ }^{1}$ Department of Chemistry and Biochemistry, Hunter College and the Graduate Center of the City University of New York, 413 East 69th \\ Street, New York, NY, 10021, USA \\ ${ }^{2}$ Department of Radiology, Memorial Sloan Kettering Cancer Center, 1275 York Avenue, New York, NY10065, NY, USA
}

\begin{abstract}
Due to their remarkable selectivity and specificity for cancer biomarkers, immunoconjugates have emerged as extremely promising vectors for the delivery of diagnostic radioisotopes and fluorophores to malignant tissues. Paradoxically, however, these tools for precision medicine are synthesized in a remarkably imprecise way. Indeed, the vast majority of immunoconjugates are created via the random conjugation of bifunctional probes (e.g., DOTA-NCS) to amino acids within the antibody (e.g., lysines). Yet antibodies have multiple copies of these residues throughout their macromolecular structure, making control over the location of the conjugation reaction impossible. This lack of site specificity can lead to the formation of poorly defined, heterogeneous immunoconjugates with suboptimal in vivo behavior. Over the past decade, interest in the synthesis and development of site-specifically labeled immunoconjugates-both antibody-drug conjugates as well as constructs for in vivo imaging - has increased dramatically, and a number of reports have suggested that these better defined, more homogeneous constructs exhibit improved performance in vivo compared to their randomly modified cousins. In this two-part review, we seek to provide an overview of the various methods that have been developed to create site-specifically modified immunoconjugates for positron emission tomography, single photon emission computed tomography, and fluorescence imaging. We will begin with an introduction to the structure of antibodies and antibody fragments. This is followed by the core of the work: sections detailing the four different approaches to site-specific modification strategies based on cysteine residues, glycans, peptide tags, and unnatural amino acids. These discussions will be divided into two installments: cysteine residues and glycans will be detailed in Part 1 of the review, while peptide tags and unnatural amino acids will be addressed in Part 2. Ultimately, we sincerely hope that this review fosters interest and enthusiasm for site-specific immunoconjugates within the nuclear medicine and molecular imaging communities.
\end{abstract}

Key words: Positron emission tomography, PET, Single photon emission computed tomography, SPECT, Fluorescence imaging, Near-infrared fluorescence imaging, Optical imaging, Click chemistry, Site-specific conjugation, Site-selective conjugation, Bioconjugation, Bioorthogonal chemistry, Glycoengineering, Protein engineering, Antibody, Antibody fragment, Immunoglobulins, Cysteine, Maleimide, Glycans

Abbreviations: 2-keto-Gal, 2-Acetyl-2-deoxy-galactose; ADC, Antibody-drug conjugate; ALCAM, Activated leukocyte cell adhesion molecule; CEA, Carcinoembryonic antigen; CDR,

Correspondence to: Brian Zeglis; e-mail: bz102@hunter.cuny.edu 
Complementarity determining region; cysDb, Cys-diabody; Db, Diabody; DBCO, Dibenzocyclooctyne; DFO, Desferrioxamine; DHZ, Dihydroazinophthalazine; DO3A, 1,4,7Tris(carboxymethylaza)cyclododecane-10-azaacetylamide; Dol10, Dolstatin E; DOTA, $1,4,7,10-$ Tetraazacyclododecane-1,4,7,10-tetraacetic acid; DTPA, Diethylenetriaminepentaacetic acid; DTT, Dithiothreitol; EDTA, Ethylenediaminetetraacetic acid; GalNAz, N-azido-acetylgalactosamine; GalT, Galactosyltranferase; GlcNAc, N-acetylglucosamine; HER2, Human epidermal growth factor receptor 2; mAb, Monoclonal antibody; Mb, Minibody; MEA, Mercaptoethylamine; MHC, Major histocompatibility complex; MMAE, Monomethyl auristatin E; NCS, Isothiocyanate; NHS, N-hydroxysuccinimide; Ol, Optical imaging; PEG, Polyethyleneglycol; PET, Positron emission tomography; PHESELECTOR, Phage ELISA for selection of reactive thiols; PSMA, Prostate-specific membrane antigen; scFv, Single-chain variable fragment; sdAb, Single-domain antibody; SialT, Sialyltransferase; SPECT, Single photon emission computed tomography; TCEP, Tris(2-carboxyethyl)phosphine; TETA, 1,4,8,11Tetraazacyclotetradecane-1,4,8,11-tetraacetic acid; TMT-NCS, 4-(3-Isothiocyanate-4methoxyphenyl)-6,6"-bis[N,N-di(carboxymethylaminomethyl]-2,2':6',2"-terpyridine; TNC, Tenascin-C; UDP, Uridine diphosphate

\section{Introduction}

Over the last three decades, medical imaging has revolutionized cancer care, providing clinicians with the means to noninvasively acquire anatomical, functional, and biological information about tumors. Due to their remarkable affinity and specificity for cancer biomarkers, antibodies - as well as an ever-growing array of antibody fragments - have played an increasingly important role in this field (Fig. 1) [1, 2]. Indeed, antibody conjugates bearing a wide range of reporters - ranging from $\mathrm{Zr}-89$ for positron emission tomography (PET) to near-infrared fluorophores for optical imaging (OI) - have been successfully developed and translated to the clinic $[3,4]$.

Yet paradoxically, these agents designed to enable "precision medicine" are synthesized in a rather imprecise manner. At present, the vast majority of bioconjugation techniques rely on reactions between bifunctional probes and amino acids, typically lysines (Fig. 2a, b) [5-7]. For example, in the case of $\mathrm{Zr}$-89-labeled antibodies for PET imaging, an isothiocyanate-bearing derivative of the $\mathrm{Zr}-89$ chelator desferrioxamine (DFO-NCS; Fig. 3) is conjugated randomly to lysines in the immunoglobulin [6]. However, antibodies possess varying numbers of these residues distributed throughout their macromolecular structure. Thus, controlling the molecular location of these conjugation reactions and the number of conjugations per antibody is impossible.

These random bioconjugation approaches produce immunoconjugates that are poorly defined and heterogeneous on three different levels [8-10]. First, a single conjugation reaction using these methods will produce a product with a range of degrees of labeling. For example, the total population of an immunoconjugate with an average loading of 3 chelators/monoclonal antibody $(\mathrm{mAb})$ will include subpopulations with degrees of labeling ranging from 0 to well above 3. Second, even immunoconjugates that possess identical degrees of labeling are likely to be regioisomers. If, for example, we assume an antibody has 40 available lysines, an immunoconjugate with a degree of labeling of 2 chelators $/ \mathrm{mAb}$ is actually a mixture of up to 780 different regioisomers, while an immunoconjugate with a degree of labeling of 3 chelators $/ \mathrm{mAb}$ is actually a mixture of over 10,000 different regioisomers! And third, random conjugation strategies present batch-to-batch reproducibility issues. Even if two batches of an immunoconjugate possess the same degree of labeling, it is extremely unlikely that these two batches are composed of the exact same mixture of regioisomers.

This heterogeneity should not be dismissed as an academic issue. Each regioisomer has a unique set of chemical, biological, and pharmacological traits. An antibody with a single fluorophore attached to a lysine in the $\mathrm{C}_{\mathrm{H}} 3$ region, for example, will likely exhibit in vivo pharmacokinetics different from that of an antibody bearing five fluorophores attached to lysines in the $V_{H}$ and $C_{H} 1$ domains. Furthermore, without the ability to control the precise location of the conjugation reactions, cargoes may become appended to the antigen-binding domains of the antibody, thus impairing the immunoreactivity of the conjugate [11]. Taken together, these issues can have adverse effects on the in vivo performance of immunoconjugates, resulting in suboptimal pharmacokinetics, decreased accumulation in target tissues, and increased uptake in healthy tissues. There are logistical drawbacks to random bioconjugation methods as well. In the absent of precise control over the modification process, every new immunoconjugate must undergo extensive optimization, a process that can be costly, time-consuming, and tedious.

In response to these problems, the last decade has played witness to a great deal of research into the development of methodologies for the site-specific modification of antibodies $[8,12-16]$. On the most basic level, the key to any site- 


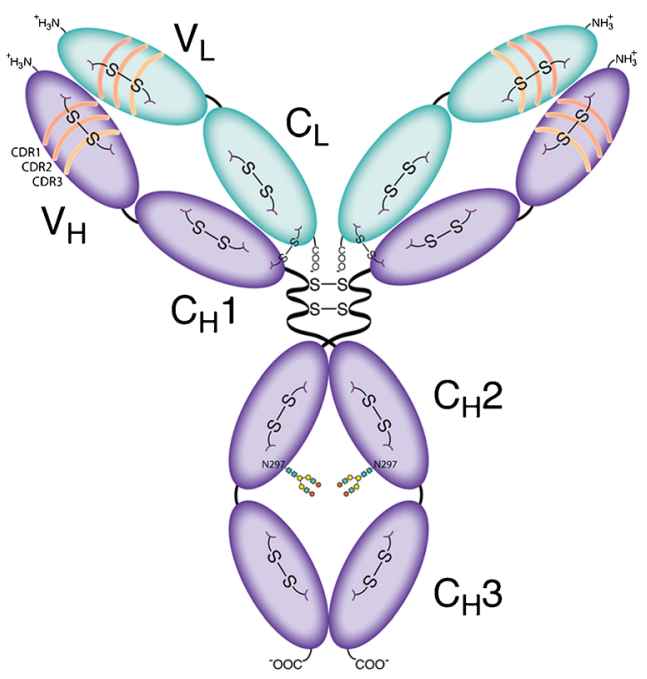

Detailed IgG Structure
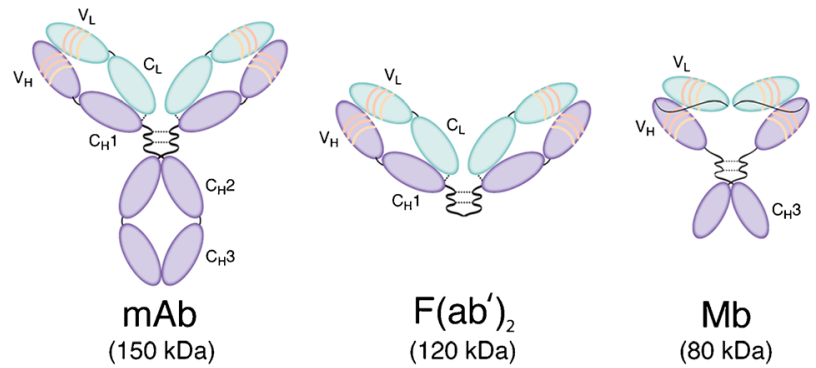

$\mathrm{F}\left(\mathrm{ab} \mathrm{b}^{\prime}\right)_{2}$

$(120 \mathrm{kDa})$

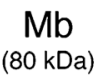

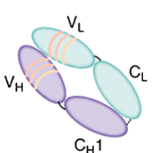

$\mathrm{Fab}$

$(55 \mathrm{kDa})$

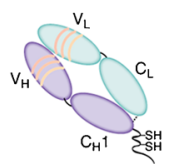

$\mathrm{Fab}^{\prime}$

$(55 \mathrm{kDa})$

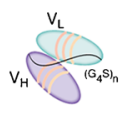

$\mathrm{scFV}$

$(28 \mathrm{kDa})$
$(80 \mathrm{kDa})$

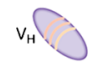

sdAbs

(15 kDa)

Fig. 1 Detailed structural schematic of a full-length IgG as well as an assortment of antibody fragments.

specific bioconjugation strategy is selectivity. A variant of the cargo molecule-whether a chelator, fluorophore, drug, or prosthetic group-must be designed to react chemoselectively with a specific site or sites in the structure of the antibody. Effective site-specific bioconjugation strategies have been developed using a wide range of pathways to achieve chemoselectivity, including bioorthogonal organic transformations, click chemistry, and enzymatic reactions [17-22]. Regardless of the specifics, however, the end result in every case is straightforward: the creation of better defined, more homogeneous immunoconjugates.

Practically speaking, these site-specific modification strategies offer a number of important advantages over traditional random modification methods. First, site-specific approaches reproducibly yield better defined and more homogeneous immunoconjugates, simultaneously eliminating the problems of heterogeneity and irreproducibility created by random approaches. Second, because sitespecific procedures enable the precise control over the molecular location of the conjugation reaction, these methods prevent the inadvertent attachment of cargoes to the antigen-binding domains of the antibody. Third, it is almost certain that regulatory agencies would look more favorably on well-defined, homogeneous immunoconjugates compared to the complex, heterogeneous mixtures of constructs created using random conjugation strategies. Finally, and perhaps most importantly, a number of intriguing reports have found that site-specifically modified immunoconjugates exhibit superior in vivo behavior to their traditionally synthesized cousins, boasting more favorable pharmacokinetics, higher uptake in target tissues, and lower background accumulation in healthy tissues [14, 23-27].

In this two-part review, it is our goal to provide an overview of the various methods that have been developed to create site-specifically modified immunoconjugates for
PET, single photon emission computed tomography (SPECT), and fluorescence imaging. Furthermore, due to the advent of antibody fragments as smaller, more pharmacokinetically rapid alternatives to full-length IgGs, we have decided to include immunoconjugates based on these constructs as well [28, 29]. Given the tremendous amount of work to cover, we have divided this review into two parts. In Part 1, we will begin with an introduction to the structure of antibodies and antibody fragments, followed by detailed discussions of the site-specific modification strategies based on cysteine residues and glycans. In Part 2, we will shift our focus to site-specific bioconjugation approaches based on peptide tags and unnatural and noncanonical amino acids. In Part 2, we will also offer a broad overview of the advantages and disadvantages of the various approaches to conjugation as well as some rumination on the direction of the field as a whole. Importantly, there are a number of cases in which a given site-specific modification strategy has been used in the creation of an antibody-drug conjugates (ADCs) but has not yet been employed to create an immunoconjugate for imaging. In these cases, we have chosen to discuss the approach in question-if only briefly - in order to increase the breadth of this work and encourage the application of these methods to imaging agents. For readers specifically interested in the construction of ADCs, we recommend a few recent and extremely wellwritten reviews $[8,14,16]$. In addition, we have found a small number of reports detailing the creation of sitespecifically labeled antibodies for radioimmunotherapy; given that the development of agents for nuclear imaging and targeted radiotherapy often go hand in hand, we have included these examples as well. Finally, we would also like to issue a small caveat. The development of site-specific antibody modification strategies is a rapidly growing field. We have tried to cover as many of the different approaches as we could find in the literature. However, it is all but 
a<smiles>[R8]CNC([R2])=O</smiles><smiles>[R]CSC1CC(=O)N(C[R])C1=O</smiles>

e

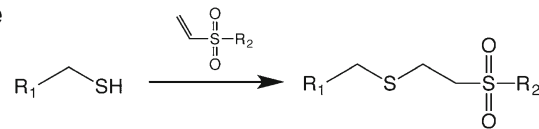

$\mathrm{g} \mathrm{SHH}_{\mathrm{SH}}^{\mathrm{SH}}$<smiles>[R2]CN1C(=O)C2=C(SCCCCS2)C1=O</smiles>

i

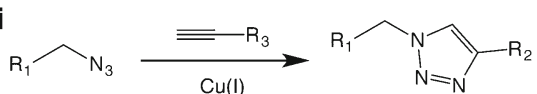

$\mathbf{k}$ $\mathrm{R}_{1} \curvearrowright \mathrm{OH} \stackrel{\mathrm{NaIO}_{4}}{\longrightarrow} \underset{\mathrm{R}_{1}}{\longrightarrow} \overbrace{\mathrm{H}}^{\mathrm{O}}$ b<smiles>[R]CNC(=S)Nc1ccc(C[R7])cc1</smiles>

d

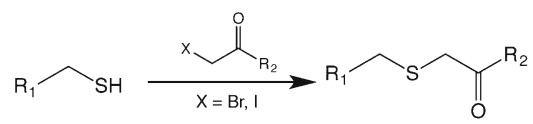

f<smiles>[R6]CSC[R]</smiles>

h

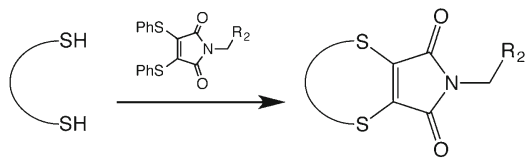

j

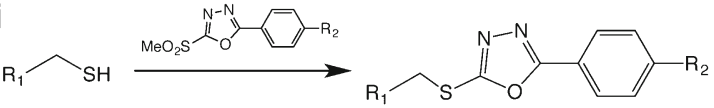

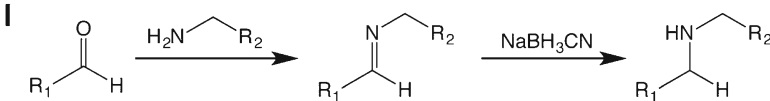

m

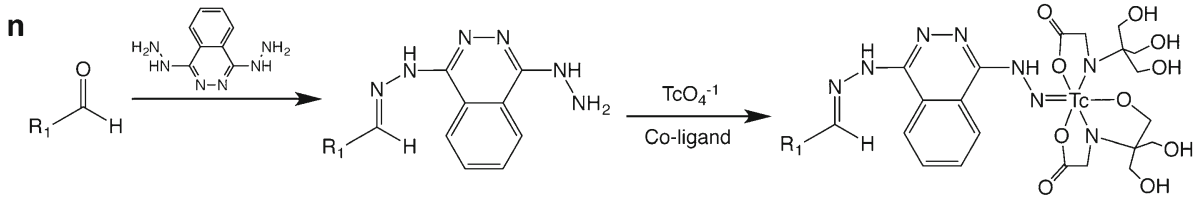

o<smiles>[R6]O/N=C/C=C/C([B])=O</smiles><smiles>[R7]OC1Cc2ccccc2C#Cc2ccccc21</smiles>

p<smiles>[R6]ON=C(C)CCCCC</smiles>

Fig. 2 The basic chemical reactions underpinning the bioconjugation strategies discussed in this work.

certain that we have missed at least one report, most likely more. To the authors of these works, we humbly apologize in advance.

\section{Immunoglobulin Structure}

\section{Antibodies}

Discovered in the late nineteenth century as toxinneutralizing agents in the blood of animals infected with diphtheria, antibodies are globular proteins produced by the immune system, hence the term "immunoglobulin" [30]. As seen in electron micrographs, antibodies are Y-shaped molecules with a bifurcated end joined to a stalk by a flexible hinge region (Fig. 1) [31]. The forked end consists of the antigen-binding fragments - i.e., the Fab region - that define the specificity of the antibody for its antigen target, while the stalk - i.e., the $\mathrm{Fc}$ region-interacts with receptors on immune effector cells. Structurally speaking, immunoglobulins are heterodimeric proteins composed of two $\sim 55 \mathrm{kDa}$ polypeptide chains dubbed the "heavy" chains (H) and two $\sim 25 \mathrm{kDa}$ polypeptide chains dubbed the "light" chains (L). Based on the specific composition of the heavy chains, immunoglobulins can be categorized into a number 
<smiles>O=C(O)CN(CCN(CC(=O)O)CC(=O)O)CC(=O)O</smiles>

EDTA<smiles>O=C(O)CN1CCN(CC(=O)O)CCN(CC(=O)O)CCN(CC(=O)O)CC1</smiles>
DOTA<smiles>O=C(O)CN1CCCN(CC(=O)O)CCCN(CC(=O)O)N(CC(=O)O)CCC1</smiles>

TETA<smiles>O=C(O)CN(CCNCCN(CC(=O)O)CC(=O)O)CC(=O)O</smiles>

DTPA<smiles></smiles><smiles>CC(=O)N(C)NC(=O)CCC(=O)N(O)SC(=O)NC(=O)CCC(=O)N(O)CCCCCN</smiles>

Desferrioxamine (DFO)<smiles>O=C(O)CN1CCN(CC(=O)O)CCN(CC(=O)O)CCN(CC(=O)O)CC1</smiles>

D03A<smiles>COc1ccc(-c2cc(-c3cccc(CN(CC(=O)O)CC(=O)O)n3)nc(-c3cccc(CN(CC(=O)O)CC(=O)O)n3)c2)cc1</smiles>

TMT

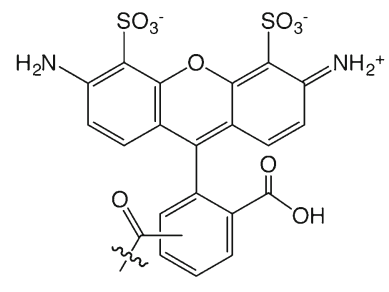

AlexaFluor $^{\mathrm{TM}} \mathbf{4 8 8}$

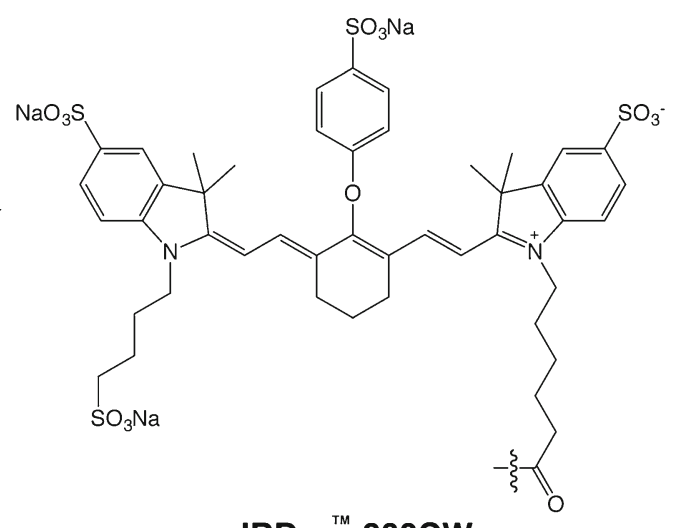

IRDye $^{\mathrm{TM}} 800 \mathrm{CW}$<smiles>CCC(C)C(C(CC(=O)N1CCC[C@H]1[C@H](C)[C@H](C)C(=O)NC(C)C(O)c1ccccc1)OC)N(C)C(=O)[C@@H](NC(=O)[C@@H](NC)C(C)C)C(C)C</smiles>

MMAE<smiles>CCC(C)[C@H](NC(=O)C(NC(=O)C(C(C)C)N(C)C)C(C)C)C(CC(=O)N1CCC[C@H]1[C@H](OC)[C@@H](C)C(=O)NC(Cc1ccccc1)c1nccs1)OC</smiles>

Dol10

Fig. 3 Selected chelators and cargoes used in the site-specifically labeled immunoconjugates discussed in this work.

of different isotypes, including $\operatorname{IgA}$, $\operatorname{IgM}$, $\operatorname{IgD}$, IgE, and $\operatorname{IgG}$. In contrast, there are only two types of light chains: kappa $(\kappa)$ and lambda $(\lambda)$. For the sake of simplicity, we will limit this discussion of antibody structure to IgG molecules, the most abundant isotype in antiserum.

The heavy and light chains are composed of a number of segmented domains, which are broadly categorized as the constant (C) and variable (V) domains. Each domain has 110-130 amino acid residues, averaging a molecular weight of $12.5 \mathrm{kDa}$ [32]. While the heavy chain of a typical IgG has three $\mathrm{C}$ domains $\left(\mathrm{C}_{\mathrm{H}} 1, \mathrm{C}_{\mathrm{H}} 2, \mathrm{C}_{\mathrm{H}} 3\right)$ and one $\mathrm{V}$ domain $\left(\mathrm{V}_{\mathrm{H}}\right)$, the light chain is made up of one $\mathrm{V}$ domain $\left(\mathrm{V}_{\mathrm{L}}\right)$ and one $\mathrm{C}$ domain $\left(\mathrm{C}_{\mathrm{L}}\right)$. Taken together, there are a total of 12 individual domains per $\operatorname{IgG}$ molecule. These domains are organized further into a three-dimensional structure which is primarily held together by noncovalent hydrophobic interactions, hydrogen bonds, and van der Waals forces. However, covalent disulfide bonds play a very important 
role in the structure of IgGs as well. Typically, IgGs possess 16 disulfide bonds formed between 32 cysteine residues. Four of these linkages are interchain disulfide bonds: two in the flexible hinge region and two that connect the constant domains within the Fab region: $\mathrm{C}_{\mathrm{H}} 1$ with $\mathrm{C}_{\mathrm{L}}$. The remaining 12 are intrachain disulfide bonds, with one linkage per domain. Considering the topic at hand, it is important to note that the abundance of hydrophobic interactions between the various domains allows for the inter- and intrachain disulfides to be partially reduced or even substituted without compromising the structural integrity of the antibody [33]. The key to the extraordinary specificity of antibodies lies in the $\mathrm{V}$ domains of the immunoglobulin. The $\mathrm{V}$ domains of the Fab region are composed of four framework regions interspersed with three hypervariable complementarity determining regions: CDR1, CDR2, and CDR3 [34, 35]. The framework regions principally contribute to the stability and interdomain interactions between the heavy and light chain domains. The unique antigen-binding pocket, or paratope, is created by the three-dimensional organization of the CDRs of both the $\mathrm{L}$ and $\mathrm{H}$ chains and ultimately confers diversity and specificity to an antibody for its target antigen [10].

The posttranslational glycosylation of antibodies adds an additional structural element and has important implications for their function as well [36]. Antibodies are glycoproteins, and different isotypes are characterized by different degrees of glycosylation. IgGs, for example, are known to have an overall $3 \%$ carbohydrate content, with a conserved glycosylation site at $\mathrm{N} 297$ on both $\mathrm{C}_{\mathrm{H}} 2$ domains within the Fc region. Glycans attached to this residue comprise a complex biantennary heptasaccharide unit formed by Dgalactose (Gal), $N$-acetyl-D-galactosamine (GalNAc), $N$ acetylglucosamine (GlcNAc), L-fucose (Fuc), and D-mannose (Man). In addition to contributing to the proper folding and solubility of immunoglobulins, glycans impact the downstream activation of immune effector functions by virtue of their interaction with the complementary $\mathrm{Fc}$ receptors on immune effector cells [37].

\section{Antibody Fragments}

As early as 1950, experiments by Porter et al. found that antibodies can be digested with enzymes to produce two independent $\mathrm{Fab}$ fragments and an Fc fragment [38-40]. Not long after, it was found that peptic digestion of antibodies yielded two products: a dimeric $\mathrm{F}\left(\mathrm{ab}^{\prime}\right)_{2}$ and an $\mathrm{Fc}$ fragment [41]. Purification of these moieties revealed that the isolated $\mathrm{Fab}$ and $\mathrm{F}\left(\mathrm{ab}^{\prime}\right)_{2}$ units were capable of binding to the target antigen of the parent antibody with specificity and selectivity, albeit with different valencies. This work has led to the emergence of antibody engineering and the production of a variety of antibody fragments based on the smallest, completely functional monovalent antigen-binding unit of an IgG: the single-chain variable fragment (scFv) ( 28 kDa) [28, 42].
From an imaging point of view, antibody fragments offer a number of enticing traits, including (a) rapid clearance from systemic circulation, (b) better extravasation and tumor penetration than full-length antibodies, and (c) immunologic inertness due to the absence of the Fc region. Furthermore, the recombinant technology used to produce these fragments provides an opportunity to introduce genetic modifications to improve target avidity and binding valence as well as to facilitate bioconjugation [28]. Indeed, beyond $\mathrm{F}\left(\mathrm{ab}^{\prime}\right)_{2}, \mathrm{Fab}$, and $\mathrm{scFv}$ fragments, a variety of other engineered constructs have been created, including diabodies $(\mathrm{Db})$, cys-diabodies (cysDb), minibodies (Mb), single-domain antibodies (sdAb), and $\mathrm{scFv}-\mathrm{Fc}$ fusion constructs (Fig. 1) [28, 42-44]. Immunoconjugates based on these fragments have demonstrated significant promise in preclinical imaging investigations; admittedly, however, the clinical potential of engineered fragments has yet to be fully realized.

\section{Cysteine Residues}

Cysteine residues and their thiol functional groups have long been attractive targets for the selective modification of peptides and proteins [45]. Much like the lysines targeted in traditional bioconjugation approaches, cysteine residues occur naturally within antibodies; importantly, however, antibodies contain fewer cysteines than lysines, and these cysteine residues occur only at specific and well-defined locations within the immunoglobulin. From a bioconjugation standpoint, the most enticing trait of cysteines is their ability to undergo highly selective ligations via Michael additions and alkylations. The most commonly employed thiolreactive moiety is the maleimide, which undergoes a Michael addition with the sulfhydryl group to form a maleimidyl-thioether bond (Fig. 2c). However, many have argued that this linkage is less than ideal for bioconjugation due its instability to hydrolysis and propensity for exchange reactions with endogenous, thiol-bearing proteins. As a result, significant effort has been dedicated to the development of more efficient thiol-reactive constructs (Fig. 2d-h) $[22,46,47]$. As we have discussed, full-length IgGs typically contain 32 cysteine residues that combine to form 12 intrachain and 4 interchain disulfide bridges. Naturally, these numbers go down when considering antibody fragments: Fab fragments, for example, possess four intrachain and one interchain disulfide bridges. Interchain disulfides are the more attractive natural conjugation targets, both because they are more easily reduced than their intrachain counterparts and because of their position far from the antigenbinding domains. However, some laboratories have sought to move past the modification of naturally occurring disulfides, instead using genetic engineering to incorporate free cysteine residues into immunoglobulins with the express purpose of creating conjugation sites (Fig. 4). In this section, we will discuss approaches that have been developed to sitespecifically modify full-length IgGs and smaller fragments using both native and engineered cysteine residues. 


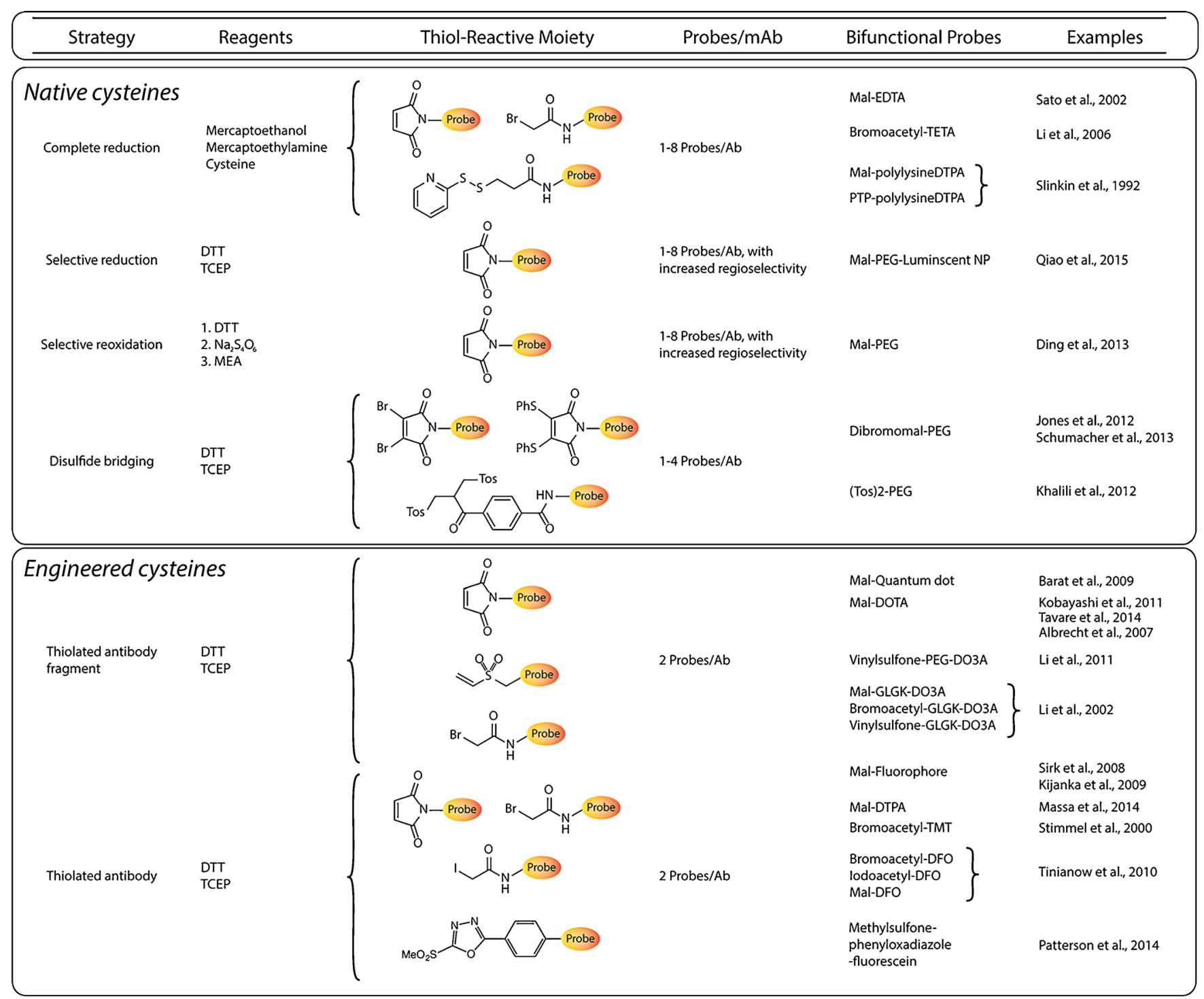

Fig. 4 Table of site-specific bioconjugation strategies based on the modification of cysteine residues.

\section{Native Cysteines}

Without a doubt, the simplest thiol-based site-specific modifications are those made to native cysteines. For example, in 2002, Sato et al. created an anti-tenascin-C (TNC) Fab' via the digestion of an anti-TNC IgG with pepsin and the subsequent reduction of the disulfides in the hinge region [48]. The free sulfhydryl groups were then conjugated to a maleimide-bearing variant of ethylenediaminetetraacetic acid (EDTA), and the unreacted thiols were quenched with iodoacetamide, yielding a conjugate with a degree of labeling of 1.4 EDTA/Fab' (Fig. 3). After radiolabeling the Fab'-EDTA construct with In-111, the radioimmunoconjugate was successfully employed for in vivo imaging in a murine model of myocarditis. Using a very similar strategy, another laboratory created a CA125targeting Fab' fragment from the mouse IgG B43 [49]. In this case, however, instead of a maleimide-bearing construct, the researchers employed a bifunctional variant of 1,4,8,11-tetraazacyclotetradecane-1,4,8,11-tetraacetic acid (TETA) (Fig. 3) with a pendant bromoacetamide group (BAT) for conjugation to the free, hinge region thiols. The TETA-modified Fab' $^{\prime}$ was then radiolabeled with $\mathrm{Cu}-67$, and it was determined that the completed radioimmunoconjugate possessed immunoreactivity comparable to the unmodified Fab'. However, no reports of in vivo experimentation with the $\left[{ }^{67} \mathrm{Cu}\right] \mathrm{TETA}-\mathrm{Fab}^{\prime}$ construct could be found in the initial report or any follow-up publications. In a third example, over 20 years ago, Slinkin et al. created an anti-carcinoembryonic antigen (CEA) Fab' via the digestion of a full-length $\operatorname{IgG}$ with pepsin and the reduction of the hinge region disulfides of the $\mathrm{F}\left(\mathrm{ab}^{\prime}\right)_{2}$ intermediate with mercaptoethylamine (MEA) [50]. The authors then "activated" the Fab' using Ellman's reagent (DTNB), isolated the reactive Fab'-TNB, and reacted the fragment with two different diethylenetriaminepentaacetic acid (DTPA)-bearing polylysine constructs: one bearing a maleimide to create a thioether linkage and another 
containing a (pyridyldithio)proprionate functionality geared toward the production of a reducible disulfide bridge. After radiolabeling the immunoconjugates with In111, a biodistribution study was carried out in mice bearing LS174T human colorectal carcinoma xenografts. Interestingly, while the thioether-linked radiotracer was shown to target the tumor efficiently, the disulfide-bridged compound resulted in high levels of kidney uptake and poor tumor targeting, likely the result of the in vivo cleavage of the S-S linkage between the radiometal and the antibody.

While the methods described above work very well for the modification of $\mathrm{Fab}^{\prime}$ fragments, they are not appropriate for intact antibodies. After all, IgGs contain four interchain disulfide bridges, and their nonspecific reduction can create as many as eight different free cysteines [51]. Needless to say, the modification of an antibody bearing eight different conjugation sites hardly qualifies as site-specific. In order to circumvent this issue, a number of laboratories have employed strategies geared toward the selective reduction of disulfide linkages [52]. In an excellent example, Sun et al. explored these possibilities during their efforts to sitespecifically conjugate a maleimide-bearing variant of monomethyl auristatin E (MMAE) to an anti-CD30 mAb [53]. The authors report that the reducing agents dithiothreitol (DTT) and tris(2-carboxyethyl)phosphine (TCEP) can preferentially reduce the disulfide bonds bridging the heavy and light chains when used in small amounts. Interestingly, it was also found that the same disulfide bridges can be preferentially oxidized when the fully reduced $\operatorname{IgG}$ is subjected to reoxidation. Armed with this information, the authors were able to create a variety of ADCs and test their performance in vitro and in vivo. It is important to note that the isomeric homogeneity of these constructs ranged from 60 to $90 \%$, values that are impressive yet certainly leave room for improvement.

Most of the strategies discussed above are accompanied by the loss of interchain disulfide bridges. While this is generally tolerated, it is far from ideal, as these interchain links confer stability to the antibodies. Two different groups in the UK have circumvented this issue by employing bifunctional constructs that are capable of attaching a cargo to the immunoglobulin while also establishing a covalent interchain link. In one case, this was achieved through the use of a polyethyleneglycol (PEG)-modified dibromomaleimide moiety capable of performing two separate nucleophilic substitutions with the cysteines that had once formed an interchain disulfide bond (Fig. 2g) [54]. In the other example, the authors employed a PEGcontaining bisulfone group that is likewise capable of covalently relinking the erstwhile disulfide thiols [55]. Finally, Schumacher et al. have also used divalent maleimides - specifically dibromomaleimides and dithiophenolmaleimides - to functionalize antibody fragments while retaining a covalent crosslink where a disulfide once existed (Fig. 2g-h) [56].

\section{Engineered Cysteines}

An alternative to the use of native cysteine residues lies in the genetic incorporation of engineered cysteines as bespoke modification sites. This approach comes with both advantages and disadvantages. On the plus side, it allows the native cysteine residues of the immunoglobulin to remain intact, thereby eliminating the possibility of any harm to the antibody. In addition, the use of engineered thiol sites allows the researcher to precisely tailor both the location and number of conjugation sites. On the other hand, it has been shown that free, unpaired cysteine residues can spontaneously oxidize to form undesired disulfide bridges, leading to aggregation and structural modifications [57, 58]. Moreover, the location of the incorporation site must be chosen very carefully in order to eliminate the risk of interfering with the antigen-binding domains. In response to these issues, Junutula et al. developed the phage ELISA for selection of reactive thiols (PHESELECTOR) biochemical assay, a procedure that provides information on the influence that the site of the introduced cysteine has on antigen-binding affinity as well as the ability to covalently modify the thiol in question [59]. Finally, the genetic engineering of immunoglobulins undeniably adds complexity and expense to the synthetic process as well. This is particularly true for full-length IgGs and $F\left(a b^{\prime}\right)_{2}$ fragments. However, even the most basic syntheses of diabodies, minibodies, or $\mathrm{scFv}$ require genetic engineering. Thus, in these cases, the genetic incorporation of additional cysteine residues can be achieved with relatively little added effort.

In the last few years, a number of laboratories have employed genetic engineering to create site-specifically modified immunoconjugates based on antibody fragments. In 2014, for example, Anna Wu's laboratory reported the development of anti-activated leukocyte cell adhesion molecule (ALCAM) cysDb [60]. After reduction with TCEP, these constructs were conjugated to a maleimidebearing bifunctional 1,4,7,10-tetraazacyclododecane1,4,7,10-tetraacetic acid (DOTA) to yield constructs with exactly two chelators per diabody (Fig. 3). For the sake of comparison, the cysDbs were also randomly modified using DOTA-NHS. Both immunoconjugates were successfully radiolabeled with ${ }^{64} \mathrm{Cu}$ and used for PET imaging in mice bearing ALCAM-positive and ALCAM-negative xenografts. While both $\mathrm{Cu}$-64-labeled diabodies effectively discriminated between the two tumor types, the site-specifically labeled $\left[{ }^{64} \mathrm{Cu}\right]$ DOTA-cysDb exhibited higher tumoral uptake and more favorable tumor-to-background activity concentration ratios than its randomly labeled cousin. In addition, the sitespecific labeling of the cysDb also seemed to exert a significant influence on the pharmacokinetic profile of the radioimmunoconjugate, increasing kidney uptake and decreasing liver retention compared to the randomly labeled construct.

Other laboratories have synthesized a range of sitespecifically radiolabeled fragments via reactions with $\mathrm{C}$ - 
terminal cysteines, including an anti-TNC $\left[{ }^{111} \mathrm{In}\right] \mathrm{DTPA}$ $\mathrm{scFv}$, an anti-human epidermal growth factor receptor 2 (HER2) $\left[{ }^{111}\right.$ In]DTPA-sdAb, an anti-MUC1 $\left[{ }^{111}\right.$ In]DOTAdi-scFv, and an anti-CEA $\left[{ }^{64} \mathrm{Cu}\right] \mathrm{DO} 3 \mathrm{~A}-$ GLGK-cysDb (Fig. 3) [61-64]. In a small variation on this approach, Li et al. employed DO3A-PEG $\mathrm{n}_{\mathrm{n}}$ constructs $(n=12,24$, and 48) bearing a vinyl sulfone moiety to site-specifically modify an anti-TAG-72 diabody with a C-terminal cysteine (Fig. 3 and 5a) [65]. After radiolabeling these conjugates with $\mathrm{Cu}-64$, PET imaging was performed using mice bearing LS174T xenografts, and the authors found that while all of the diabodies proved able to target the tumor, the background activity levels in the blood and kidneys were highly dependent on the length of the PEG chain. Conjugations with C-terminal cysteines have also been used for the creation of immunoconjugates for fluorescence imaging. For example, Sirk et al. used maleimide-bearing variants of AlexaFluor ${ }^{\circledR} 488$, phycoerythrin, and allophycocyanin to create anti-HER2 and anti-CD20 cysDbs for in vitro fluorescence imaging (Fig. 3) [66]. More recently, a group in the Netherlands reported the development of a series of HER2-targeting nanobodies site-specifically conjugated to the near-infrared fluorophore IRDye $800 \mathrm{CW}$ through Cterminal cysteine residues (Fig. 3) [67]. In vivo fluorescence imaging experiments using mice bearing HER2-positive SKBR3 breast cancer xenografts revealed that the sitespecifically labeled nanobodies yielded higher tumor-tobackground intensity ratios than a construct that had been randomly modified through lysine residues. Moreover, these probes were shown to possess significant promise for intraoperative imaging during the surgical resection of tumors.

In their efforts to reduce the retention of radioisotopes in the kidneys - a frequent stumbling block for radiolabeled antibody fragments - the laboratories of $\mathrm{Wu}$ and Shively provided an excellent comparative case study on the various thiol-reactive conjugation strategies [68]. In this work, the authors incorporated a GLGK tetrapeptide linker between an anti-CEA cysDb and a DO3A chelator that is designed to be cleaved specifically by the carboxypeptidase activity of kidney brush border enzymes (Fig. 3). In theory, this modification could facilitate the specific cleavage of the tetrapeptide upon the inevitable uptake of the fragment in the kidney, thereby facilitating the rapid elimination of the radiometal-chelate complex even though the diabody remains trapped in the kidney. To this end, GLGK peptides were functionalized on the N-terminus with a DO3A chelator and on the $\varepsilon$ amino group of the lysine residue with three different thiol-reactive moieties: a maleimide, a bromoacetyl group, and a vinylsulfone group. These DO3Apeptide constructs were then site-specifically attached to the $\mathrm{C}$-terminal cysteine of the diabody, producing conjugates with degrees of labeling ranging from 0.8 to 1.3 chelators/ cysDb. These constructs-along with a nonsite-specifically labeled variant-were labeled with In-111, and biodistribution experiments were performed in mice bearing
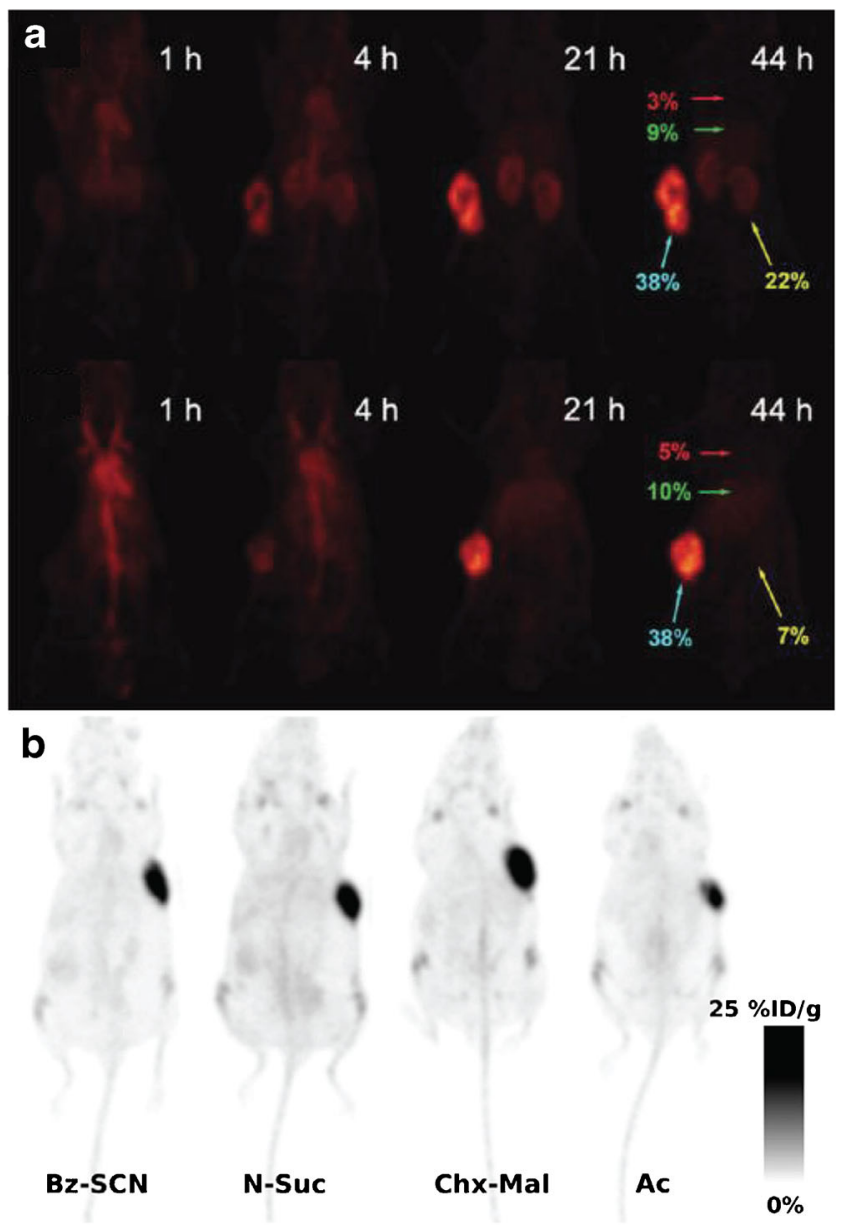

Fig. 5 a Serial PET images of site-specifically labeled $\left[{ }^{64} \mathrm{Cu}\right] \mathrm{DOTA}-\mathrm{PEG} \mathrm{24}-\mathrm{AVP04}-50$ (top) and $\left[{ }^{64} \mathrm{Cu}\right] \mathrm{DOTA}-\mathrm{PEG}_{48^{-}}$ AVP04-50 (bottom) in athymic nude mice bearing LS174T xenografts. The labels in red, green, yellow, and turquoise illustrate the \%ID/g values in the heart, liver, kidney, and tumor, respectively. Figure adapted and reprinted with the permission of Li et al. Copyright 2011 American Chemical Society [65]. b PET images of four different variants of $\left[{ }^{89} \mathrm{Zr}\right] \mathrm{DFO}$-thio-trastuzumab in mice bearing BT474 xenografts. In two of the radioimmunoconjugates, the chelator was attached using nonsite-specific conjugation methods (Bz-SCN and N-Suc), while in the other two constructs, bioconjugation was achieved using thiol-reactive variants of DFO (Chx-Mal and Ac). Figure adapted and reprinted with the permission of Tinianow et al. Copyright 2010 Elsevier Publishing Group [17].

LS174T colon cancer xenografts. As expected, high activity concentration levels were observed in the kidneys for the randomly modified conjugate $\left[{ }^{111}\right.$ In]DOTA-cysDb but also, somewhat surprisingly, the bromoacetyl-based $\left[{ }^{111}\right.$ In]DO3A-GLGK-cysDb construct. In contrast, dramatically reduced kidney uptake was observed for the conjugates created using the maleimide and vinylsulfone approaches. This clearly underscores that the conjugation strategy may have as much of a role in influencing biodistribution as the addition of the cleavable peptide. 
The incorporation of cysteines via genetic engineering has also been applied to full-length IgGs to produce what has often been dubbed "thiomAbs." Stimmel et al., for example, mutated position 442 in the $\mathrm{C}_{\mathrm{H}} 3$ domain of an IgG to replace a serine residue with a cysteine [69]. The mutant $\operatorname{IgG}$ was then partially reduced with MEA to free the engineered thiol while leaving the native disulfides untouched. This construct was then conjugated to a bromoacetamide-bearing variant of the TMT chelator to yield a final construct with between one to two chelators/ $\mathrm{mAb}$ and an immunoreactivity nearly identical to that of the unmodified antibody (Fig. 3). Much more recently, a team from Genentech developed a genetically engineered variant of trastuzumab with cysteine residues incorporated in the heavy chain [17]. This thiomAb was reduced with an excess of DTT and then partially reoxidized with dehydroascorbic acid in order to selectively prepare the engineered thiols for modification with variants of the $\mathrm{Zr}-89$ chelator desferrioxamine (DFO; Fig. 3) bearing thiol-reactive bromoacetyl, iodoacetyl, or maleimide groups (Fig. 5b). These trastuzumab-DFO immunoconjugates were found to have approximately $1.8 \mathrm{DFO} / \mathrm{mAb}$, were labeled with $\mathrm{Zr}-89$ in high yield and radiochemical purity, and were found to have immunoreactivities and stabilities comparable to constructs created using nonsite-specific conjugation methodologies. In a separate study, Boswell et al. developed a maleimide-bearing tyrosine-DOTA construct as a scaffold for the site-specific iodination of immunoconjugates. The tyrosine-DOTA moiety was first labeled with I-125 and subsequently attached to a HER2-targeting thioMab, with the ultimate aim of developing residualizing radioiodinated antibodies for both PET imaging (using I-124) and therapy (using I-131) [70].

ThiomAbs can also be enzymatically digested to afford $F\left(a b^{\prime}\right)_{2}, F a b^{\prime}$, and $F a b$ fragments bearing engineered cysteine residues. Using this approach, the same group at Genentech created a HER2-targeting thioFab [71]. This fragment was then conjugated to an F-18-labeled PEGylated maleimide moiety that had been prepared via copper-catalyzed azidealkyne click chemistry (Fig. 2i). In order to explore alternate synthetic strategies, the same radioimmunoconjugate was also synthesized in a two-step procedure based on the initial bioconjugation of an alkyne-bearing PEGylated maleimide followed by the copper-catalyzed ligation of an azidecontaining F-18-labeled synthon. However, the authors ultimately concluded that the former strategy is preferable, as it precludes any degradation of the antibody fragment by the $\mathrm{Cu}^{\mathrm{I}}$ click chemistry catalyst.

All of the cysteine-based modification strategies we have discussed offer enticing possibilities. The approaches based on the manipulation of native cysteines are refreshingly simple and require no genetic engineering, while the methods employing engineered cysteines offer unprecedented levels of regiochemical control. However, a major limitation to all these strategies lies in the suboptimal biological stability of maleimdyl thioether bonds. Other thiol-reactive constructs have been used effectively, yet the maleimide-thiol Michael addition reaction persists as the standard technology for cysteine-based conjugations. We are confident, however, that the next few years will witness increases in the use of more suitable chemical tools for thiolbased conjugations, such as phenyloxadiazole sulfones, dibromomaleimides, and dithiophenolmaleimides (Fig. $2 \mathrm{~g}-$ h, j) $[22,46,47]$.

\section{Glycans}

IgGs contain two conserved glycosylation sites-the N297 residues in the $\mathrm{C}_{\mathrm{H}} 2$ domains of the heavy chains - each bearing a biantennary, complex-type oligosaccharide chain (Fig. 6a). These heavy chain glycans have three significant advantages as a platform for site-specific modification: (1) the heavy chain $\mathrm{C}_{\mathrm{H}} 2$ domains lie far from the antigenbinding regions of the $\mathrm{IgG}$, thus minimizing the risk of inadvertently impairing the immunoreactivity of the antibody; (2) the basic chemistry of sugars differs fundamentally from that of amino acids, meaning that the glycans can be manipulated without disturbing the polypeptide chain; and (3) the biantennary nature of the two oligosaccharide chains opens the door for at least two and as many as four conjugation events per antibody.

\section{Oxidation-Based Methods}

The oldest methodologies for the site-specific modification of antibodies rely on the oxidation of the heavy chain glycans (Fig. 7) [8, 16, 72-74]. It is well known that sugars can be oxidized using periodate $\left(\mathrm{IO}_{4}{ }^{-}\right)$to create aldehydes (Fig. 2k). These aldehydes can then react selectively with nucleophiles - including amines, hydrazide, and aminooxy groups - to form covalent linkages (Fig. 2l-p). Importantly, there are two major caveats to these oxidation-based conjugation methodologies. First, some of the bonds formed via the reaction of the aldehydes with nucleophiles-for example, imine linkages - are hydrolytically unstable, and therefore, a reduction step is required to obtain stable immunoconjugates. Second, the initial treatment of the glycans with periodate is not always benign: it is known that this step may also result in the oxidation of methionine residues, which may in turn inadvertently affect the ability of the antibody to bind its antigen [75].

In 1986, Rodwell et al. first applied this method to the synthesis of site-specifically modified radioimmunoconjugates $[26,76]$. In this work, the major histocompatibility complex (MHC)-targeting antibody R9.75 was oxidized using $\mathrm{NaIO}_{4}$, coupled to one of three moieties bearing a primary amine - an I-125 labeled pentapeptide ([ $\left.{ }^{125} \mathrm{I}\right] \mathrm{GYGGR}$ ), a DTPA-bearing tripeptide (GYKDTPA), or a $p$-aminoaniline-DTPA - and finally reduced using sodium cyanoborohydride (Fig. 21). After radiolabeling with In-111, the immunoconjugates were 


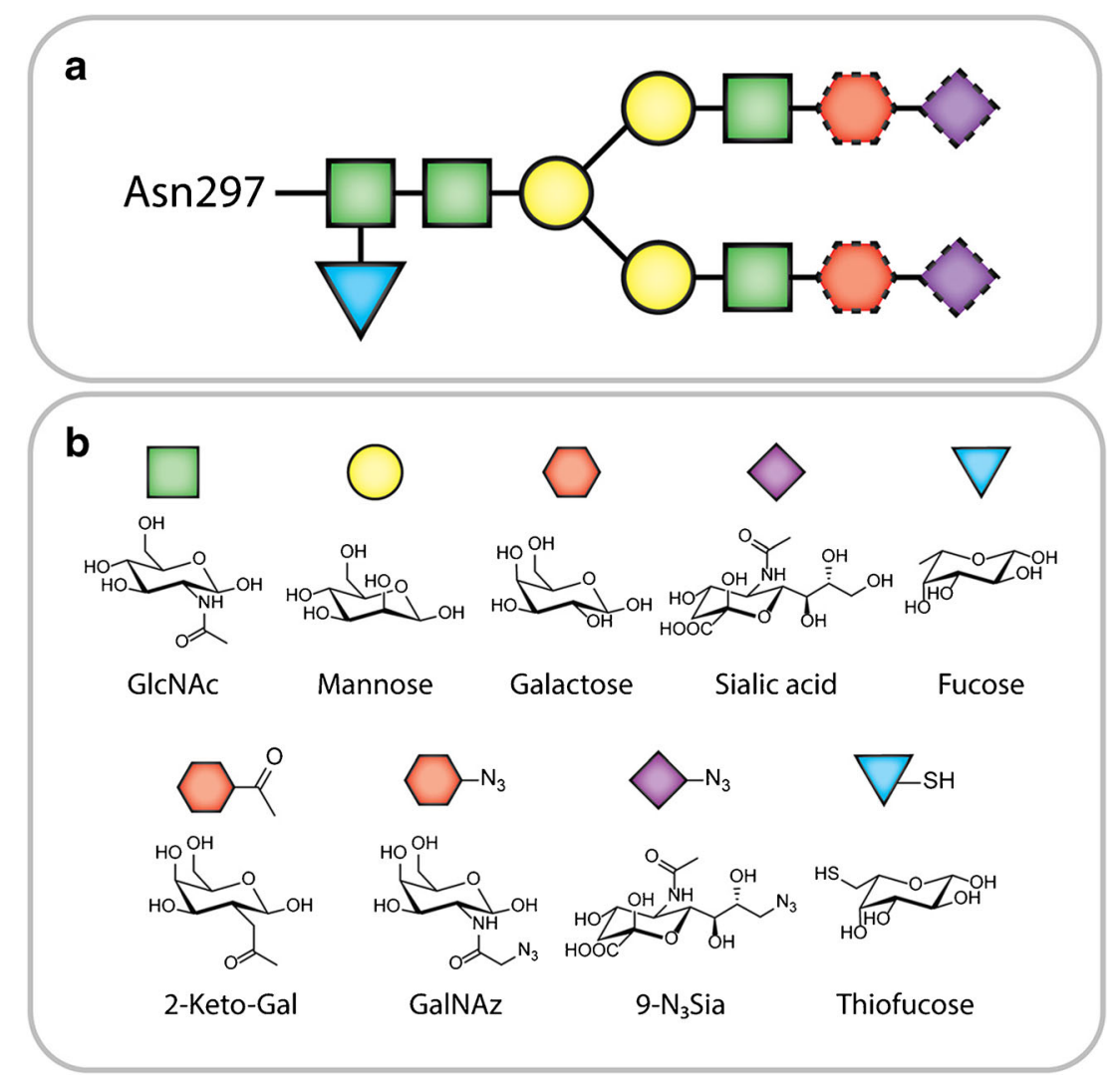

Fig. 6 a The biantennary structure of the heavy chain glycans; the dotted outlines indicate residues that are not always present in the glycans. b Structures of natural and synthetic monosaccharides.

successfully used to image mice bearing lymphoma xenografts via scintigraphy. A comparison with nonsitespecifically modified immunoconjugates illustrated that the site-specifically labeled radioimmunoconjugates targeted tumor tissue far more effectively. In more recent years, other groups have followed similar strategies for the synthesis of radioiodine-labeled constructs [74]. In addition, a number of site-specifically modified $\left[{ }^{111}\right.$ In]DTPA-labeled radioimmunoconjugates have been made using the chelator GYK-DTPA, including examples based on the anti-prostatespecific membrane antigen (PSMA) antibody 7E11-C5, the anti-carcinoembryonic antibody $\mathrm{C} 46$, the breast cancertargeting murine IgG $15 \mathrm{~A} 8$, and the TAG72-targeted antibody B72.3 (i.e., satumomab) [77-80]. All of these radioimmunoconjugates have been shown to successfully target tumor tissue in murine models of cancer, and notably, $\left[{ }^{111}\right.$ In]DTPA-satumomab has been used in the clinic in patients with colorectal cancer [80].

The aldehydes produced by the oxidation of the glycans can also react with hydrazides to form hydrazone-based linkages (Fig. $2 \mathrm{~m}$ ). While hydrazones possess greater innate stability than their imine cousins, hydrazones can also be reduced via sodium cyanoborohydride to create hydrazinebased linkages, further increasing their durability [81]. Along these lines, Stalteri et al. oxidized and coupled the PSMA-targeting antibody 7E11C5.3 with the hydrazinebearing chelator CYT-395, radiolabeled the resulting immunoconjugate with Tc-99m, and were able to effectively image prostate cancer tumors in patients (Fig. 3) [82, 83]. Using similar methods, Zuberbühler et al. employed hydrazide-bearing fluorophores to create a fluorescent immunoconjugate based on the anti-fibronectin antibody F8 [84]. Another group took a slightly different approach, modifying the anti-CD5 antibody T101 with dihydrazinophthalazine (DHZ), a compound bearing two hydrazides: while one reacted with the aldehyde to sitespecifically modify the antibody, the other was subsequently employed as part of a coordination scaffold for Tc-99m (Fig. 2n) [85]. The authors found that the resulting sitespecifically Tc-99m-labeled radioimmunoconjugate proved more stable than an analogous, traditionally conjugated variant. More recently, in an effort to develop In-111labeled immunoconjugates for Auger electron radiotherapy, Lu et al. site-specifically conjugated polymers bearing $\sim 30$ DTPA each to trastuzumab via oxidation with $\mathrm{NaIO}_{4}$, reaction with the hydrazide-bearing polymers, and reduction with $\mathrm{NaBH}_{3} \mathrm{CN}$ [86]. The resulting constructs were shown to have approximately 1.2 polymers $/ \mathrm{mAb}$ and could be successfully labeled with ${ }^{111}$ In in high yield and at higher specific activities than traditional, lysine-conjugated trastuzumab-DTPA. The authors illustrated that the modification of the In-111-labeled radioimmunoconjugate did not have a deleterious effect on the $K_{\mathrm{D}}$ of the antibody for HER2; however, the polymer-modified antibodies showed 


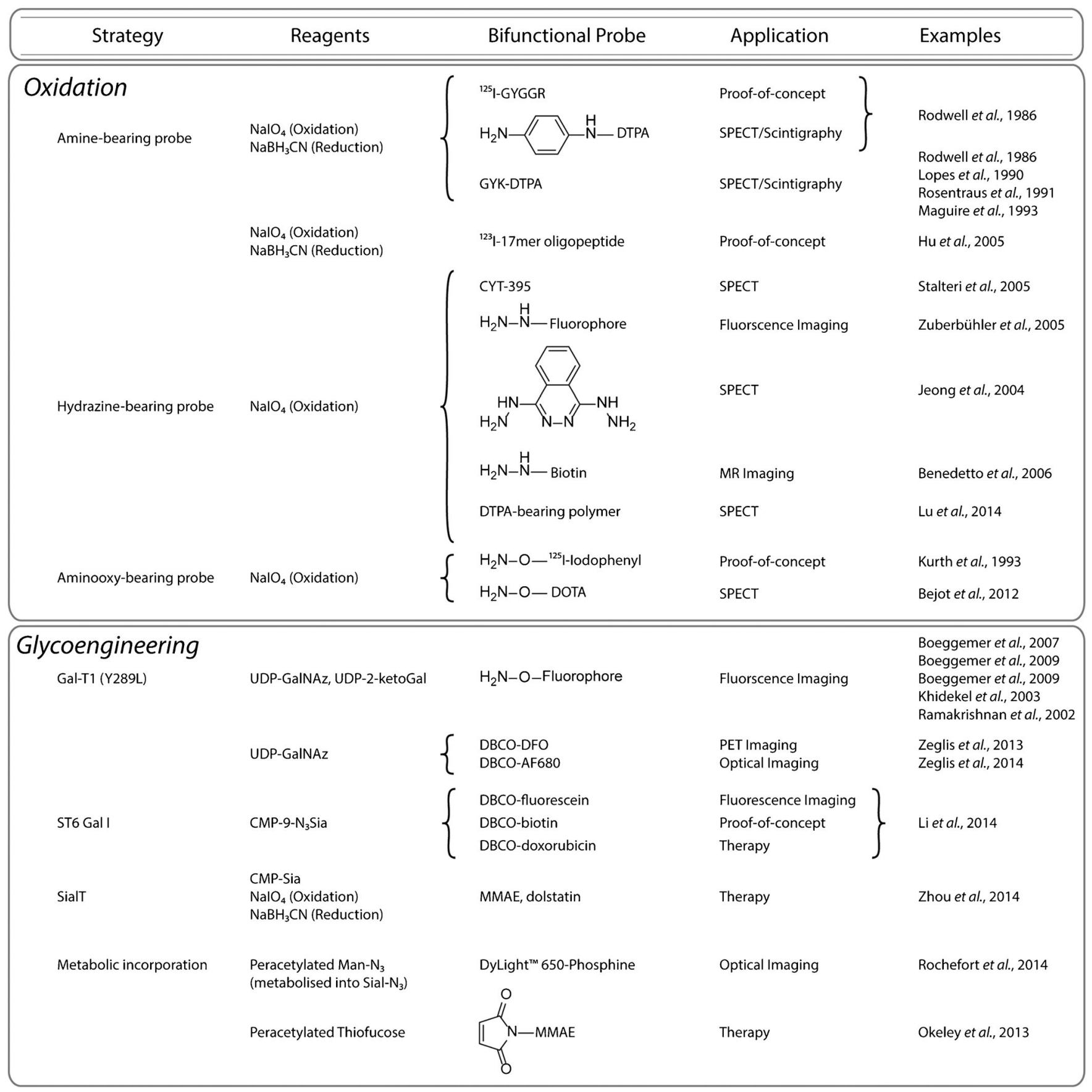

Fig. 7 Site-specific bioconjugation strategies based on the modification of glycans.

significantly increased nonspecific binding to cells that did not express the target antigen. While a follow-up study published in 2015 presented some promising in vitro results, no in vivo data was provided in either report, leaving the pharmacokinetic influence of the DTPA-laden polymers unknown for now [87].

A final variation on this theme employs O-alkyl hydroxylamines as the nucleophile in order to form aldehyde oxime ethers, which are more hydrolytically stable than imine or hydrazone products and do not require a subsequent reduction step (Fig. 2o-p) [88]. Kurth and colleagues applied this strategy to the development of a radioimmunotherapeutic agent, using an aminooxy-bearing, I-125-labeled iodophenyl construct and the mAb 35, which targets the Gold 3 epitope of the carcinoembryonic antigen [89]. The site-specifically labeled I-125 mAb 35 radioimmunoconjugates were synthesized in high specific activity and immunoreactivity and were shown to be highly stable. More importantly, in biodistribution experiments using mice bearing subcutaneous T380 colorectal cancer xenografts, the site-specifically labeled radioimmunoconjugate was found to have higher tumor 
retention and lower thyroid uptake than a variant produced using a nonsite-specific radioiodination method. Unfortunately, however, we were unable to find any in vivo therapy data using this construct or, perhaps more appropriately, a I131-bearing analog. More recently, Bejot et al. followed a similar route to label trastuzumab with an aminooxy-bearing variant of DOTA, producing a site-specifically labeled radioimmunoconjugate with $5.1 \pm 0.7 \mathrm{DOTA} / \mathrm{mAb}$, a very high immunoreactive fraction, and low nonspecific binding to HER2-negative cells. Subsequent SPECT imaging experiments using mice bearing subcutaneous, bilateral MDAMB-361 (HER2-positive) and MDA-MB-231 (HER2negative) breast cancer xenografts illustrated that the sitespecifically labeled $\left[{ }^{111}\right.$ In]DOTA-trastuzumab specifically targeted the HER2-expressing xenografts but did not offer a significant improvement over an $\left[{ }^{111}\right.$ In]DOTA-trastuzumab construct synthesized using a traditional, nonsite-specific conjugation method [90].

\section{Glycoengineering Methods}

Over the last 15 years, a number of alternative chemoenzymatic methods for the specific functionalization of glycoproteins have emerged. Using both natural and engineered enzymes, it is now possible to introduce carefully tailored sugars into the glycans to enable chemoselective modifications. Not surprisingly, this work has been enthusiastically applied to the creation of site-specifically labeled radioimmunoconjugates.

The most well-known enzyme used in these methodologies is Gal-T1(Y289L), a mutant $\beta$-1,4-galactosyltransferase developed by Qasba and coworkers. This substratepermissive galactosyltransferase facilitates the attachment of modified galactose monomers to $\mathrm{N}$-acetylglucosamine (GlcNAc) residues in the glycans (Fig. 6b) [91]. Two modified galactose residues have served as focal points: 2acetyl-2-deoxy-galactose (2-keto-Gal) and $\mathrm{N}$-azidoacetylgalactosamine (GalNAz; Fig. 6b). Each of these monomers can be used for bioorthogonal conjugations: the former can be reacted with nucleophiles in a manner similar to oxidized sugars while the latter is obviously a substrate for a variety of click chemistry transformations (Fig. 2i). Both of these unnatural sugars have been successfully incorporated into antibodies using Gal-T1(Y289L) to demonstrate proof-of-concept and to create fluorescently labeled antibodies for in vitro imaging applications [92, 93].

The first application of this Gal-T1(Y289L)-based methodology for the construction to nuclear imaging agents was published in 2013 [13]. In this work, Zeglis et al. employed a three-step modification procedure: (1) the removal of terminal galactose residues of the glycans using $\beta$-1,4-galactosidase, (2) the attachment of Gal-NAz to the sugar chains using GalT1(Y289L), and (3) the conjugation of chelator-modified dibenzocyclooctynes to the glycans via the strain-promoted azide-alkyne click reaction (Figs. $2 \mathrm{q}$ and 8 ). Using this methodology, the authors created a desferrioxamine (DFO)bearing immunoconjugate of the PSMA-targeting antibody J591 and subsequently labeled this construct with $\mathrm{Zr}-89$. In vivo PET imaging and biodistribution experiments in mice bearing subcutaneous PSMA-expressing $\mathrm{LNCaP}$ prostate cancer xenografts suggested that the site-specifically labeled radioimmunoconjugate produces slightly higher absolute tumoral uptake $(67.6 \pm 5.0 \% \mathrm{ID} / \mathrm{g}$ at $96 \mathrm{~h}$ postinjection) than an analogous agent produced using a traditional, nonsite-specific modification strategy $(57.5 \pm 5.3 \% \mathrm{ID} / \mathrm{g}$ at $96 \mathrm{~h}$ postinjection). In a subsequent study, the same group used an improved, onepot modification strategy to create a series of DFO- and AlexaFluor ${ }^{\circledR}$ 680-bearing immunoconjugates based on the huA33 antibody for the multimodal PET/near-infrared fluorescence imaging of colorectal cancer (Fig. 9) [18]. In this work, PET and fluorescence imaging experiments suggested that the site-specifically modified radioimmunoconjugates exhibited comparable - if not slightly superior - in vivo behavior compared to variants produced using non-site-specific conjugation methods.

In an effort to create more homogeneously functionalized glycans chains, Boons and coworkers have recently developed a modified chemoenzymatic strategy [94]. In this strategy, terminal galactose residues are first added to the glycans using galactosyltransferase (GalT) and uridine diphosphate (UDP)-galactose. Then, an azide-modified sialic acid monomer is incorporated into the glycans chain using sialyltransferase (ST6GalI) and the donor substrate CMP-9$\mathrm{N}_{3}$ Sia. Finally, strain-promoted azide-alkyne click chemistry is employed to attach dibenzocyclooctyne (DBCO)-modified cargoes to the antibody. This glycans remodeling strategy yielded 3.5 and 4.1 drugs $/ \mathrm{mAb}$ for the control and antiCD22 antibodies, respectively, strongly suggesting quantitative labeling of the termini of the heavy chain glycans. Using a similar strategy, Zhou et al. sought to increase the amount of sialic acid in the glycan chains via modification with GalT and then sialyltransferase (SialT) [12]. These sialic acid monomers were then specifically oxidized under mild conditions, and the resulting aldehydes were used to conjugate aminooxy-bearing variants of MMAE (Fig. 3) and dolastatin 10 (Dol10; Fig. 3).

A more elegant method for the incorporation of orthogonally functionalized sugars into glycoproteins lies in harnessing the metabolism of cells. This method consists of enriching the media of cells with modified acetyl-bearing sugars and relying on the cells themselves to incorporate these monomers into glycoproteins. In 2014, Rochefort et al. used this method to prepare an anti-CA19-9 antibody sitespecifically modified with azide groups via the metabolic incorporation of peracetylated $\mathrm{N}$-azido-acetylmannosamine [95]. After purification, the azide-modified antibody was then labeled with a phosphine-bearing fluorophore (DyLight-650) via the Staudinger ligation, and in vivo fluorescence imaging was used to show that the immunoconjugate was specifically taken up in BxPC3 pancreatic adenocarcinoma xenografts (Fig. 2r). The primary 


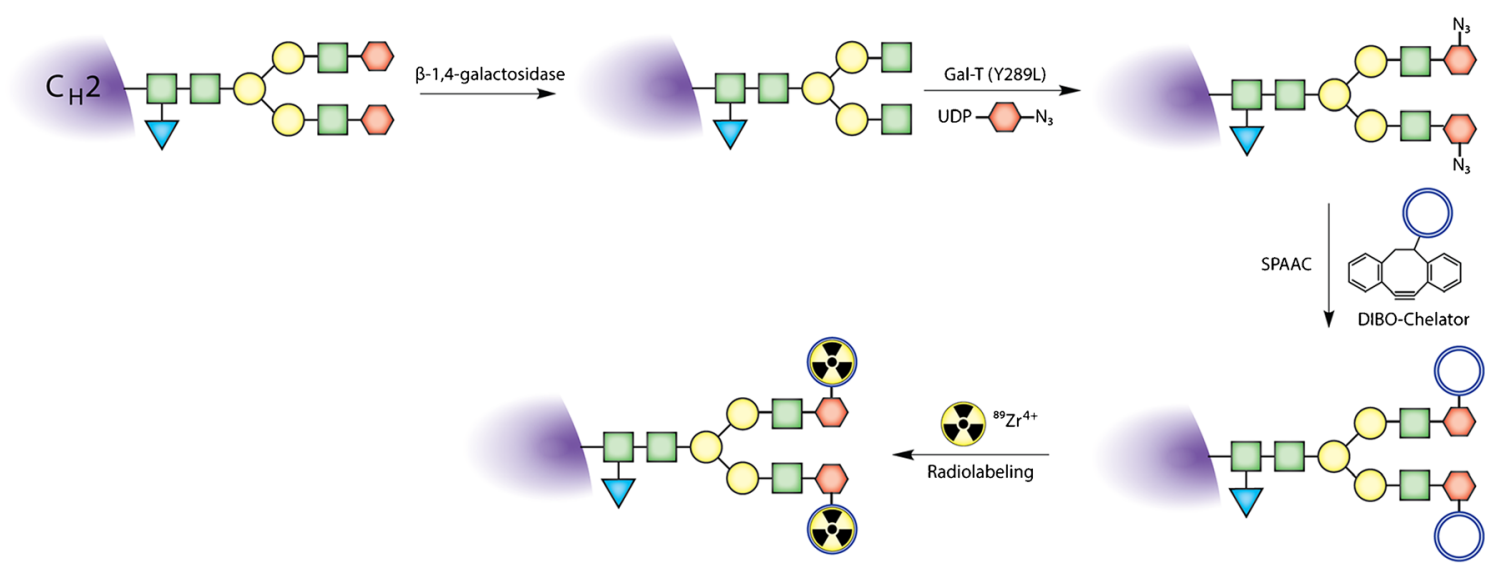

Fig. 8 Schematic of a Gal-T(Y289L)-based site-specific modification procedure.

drawback of this method, however, is the poor incorporation of functionalized sugars: a fluorophore $/ \mathrm{mAb}$ ratio of only
1:11 was achieved. Okeley and coworkers used a similar metabolic engineering approach to incorporate 6-thiofucose

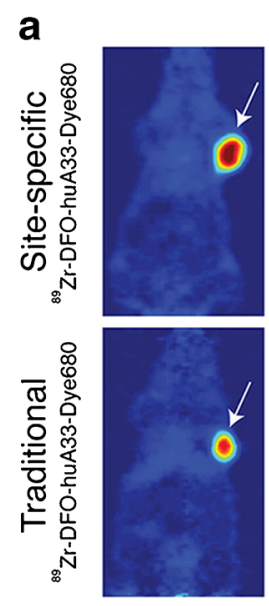

$24 \mathrm{~h}$

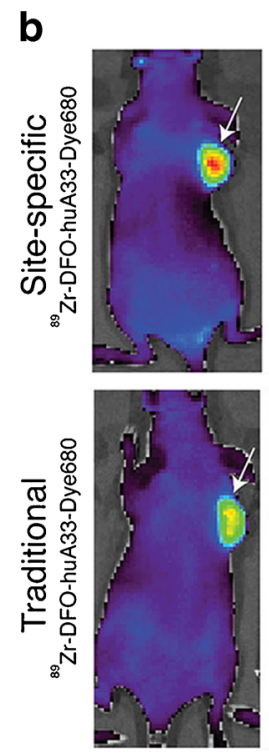

$24 \mathrm{~h}$
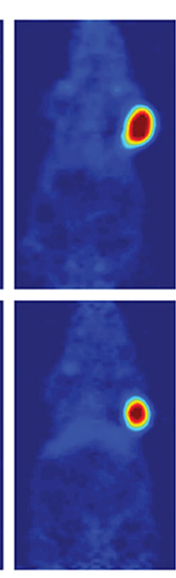

$48 \mathrm{~h}$
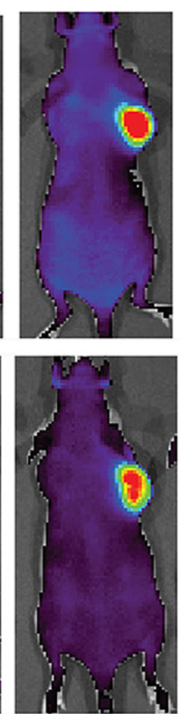

$48 \mathrm{~h}$

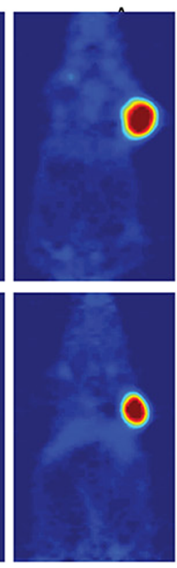

$72 \mathrm{~h}$
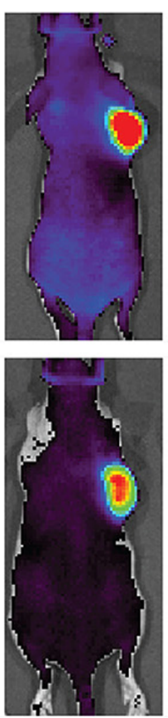

$72 \mathrm{~h}$

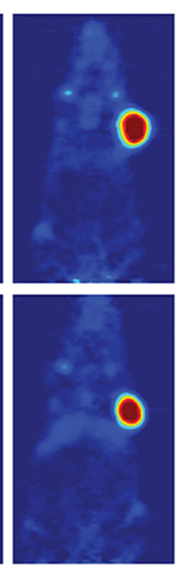

$96 \mathrm{~h}$
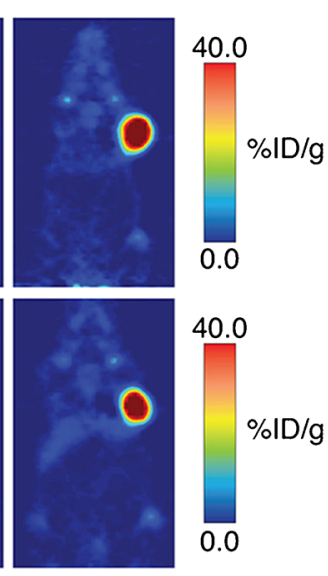

$120 \mathrm{~h}$
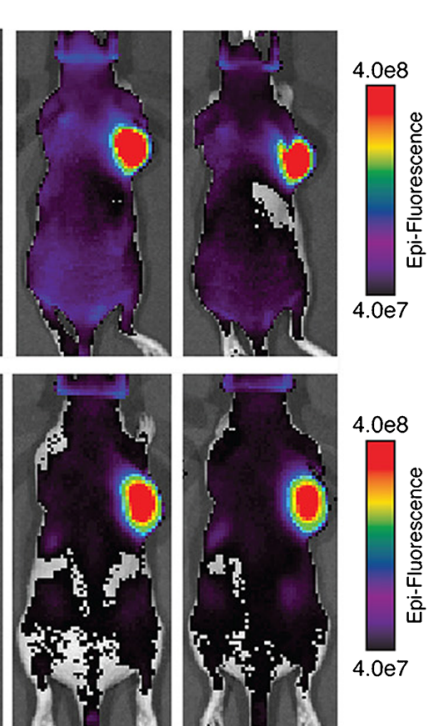

$96 \mathrm{~h}$
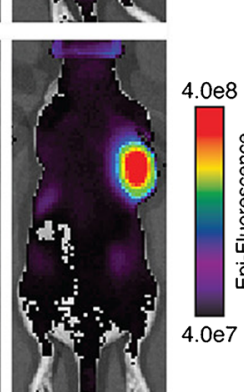

$120 \mathrm{~h}$

Fig. 9 a PET and $\mathbf{b}$ near-infrared fluorescence images of athymic nude mice bearing SW1222 tumors (white arrows) injected with either site-specifically labeled or traditionally labeled $\left[{ }^{89} \mathrm{Zr}\right] \mathrm{DFO}-\mathrm{huA33-Alexa}$ Fluor ${ }^{\circledR} 680$. In the PET images, the coronal slices intersect the center of the tumors. Figure adapted and reprinted with the permission of Zeglis et al. Copyright 2014 American Chemical Society [18]. 
site-specifically into the heavy chain glycans of the CD30targeting antibody $\mathrm{cAC} 10$ and the CD70-targeting antibody h1F6 (Fig. 6b) [96, 97]. The authors found that 1.2-1.4 thiofucose monomers were incorporated per antibody and - using a cysteine reduction/reoxidation strategy and a maleimide-bearing variant of MMAE-created immunoconjugates bearing $1.3 \mathrm{drugs} / \mathrm{mAb}$ that proved more stable to decomposition via retro-Michael addition than an analogous immunoconjugate in which the interchain disulfides had been modified.

As the recency of these citations illustrates, the use of metabolic glycans engineering to create site-specifically modified antibodies - let alone site-specifically modified antibodies for imaging applications - remains a very young field. Thus, in order to maximize the benefits of this technology, it is crucial that imaging-focused laboratories continue to investigate the use of existing metabolic engineering technologies and prove quick to leverage any new advances in the years to come $[96,97]$.

\section{Conclusion}

In the preceding pages, we have discussed an array of sitespecific bioconjugation strategies that are predicated on two simple functionalities: cysteine residues and glycans. Of course, each approach has its own intrinsic advantages and disadvantages. For example, while the modification of natural cysteine residues is both modular and straightforward, it does not offer the same degree of homogeneity and stoichiometric control as other approaches. Conversely, conjugation to engineered cysteine residues provides an exquisite level of stoichiometric and regiochemical control but requires genetic engineering, which limits its modularity and broad applicability. Likewise, while the modification of glycans via bioorthogonal click chemistry is modular, facile, and straightforward, the usefulness of this approach is necessarily limited to immunoglobulins with pendant sugar chains. Setting specifics aside, however, each of these strategies offers a route to immunoconjugates that are more homogenous and better defined than constructs created using traditional bioconjugation techniques. Furthermore, preclinical studies have shown that these site-specifically labeled immunoconjugates often boast superior in vivo behavior compared to their randomly constructed cousins. Somewhat curiously, while the clinical validation of site-specifically labeled immunoconjugates is of the utmost importance, work in this area seems to have stalled just short of the clinic. In our humble opinion, the move from bench to bedside is the most pressing imperative for the field.

In closing, it is important to note that in this installment of the review, we have only covered two of the four families of site-specific modification strategies. In Part 2 of this work, which will appear in the next issue of the journal, we will shift gears and discuss bioconjugation approaches based on peptide tags and unnatural amino acids, methods which elegantly harness chemoselective ligations and enzymatic transformations to create site-specifically modified immunoconjugates.

Acknowledgments. The authors would like to thank all of those researchers whose work has contributed to the immunoconjugates discussed in this review. We are also very grateful to the Hunter College, the Research Foundation of the City University of New York, and the NIH (4R00CA178205-02) for their generous funding.

\section{Compliance with Ethical Standards}

\section{Conflict of Interest}

The authors declare that they have no competing interests.

Open Access This article is distributed under the terms of the Creative Commons Attribution 4.0 International License (http:// creativecommons.org/licenses/by/4.0/), which permits unrestricted use, distribution, and reproduction in any medium, provided you give appropriate credit to the original author(s) and the source, provide a link to the Creative Commons license, and indicate if changes were made.

\section{References}

1. Wu AM (2009) Antibodies and antimatter: the resurgence of immunoPET. J Nucl Med 50:2-5

2. van Dongen GAMS, Visser GWM, Lub-de Hooge MN, de Vries EG, Perk LR (2007) Immuno-PET: a navigator in monoclonal antibody development and applications. Oncologist 12:1379-1389

3. Deri MA, Zeglis BM, Francesconi LC, Lewis JS (2013) PET imaging with 89Zr: from radiochemistry to the clinic. Nucl Med Biol 40:3-14

4. Frangioni JV (2003) In vivo near-infrared fluorescence imaging. Curr Opin Chem Biol 7:626-634

5. Cohen R, Vugts DJ, Stigter-van Walsum M, Visser GWM, van Dongen $\mathrm{G}$ (2013) Inert coupling of IRDye $800 \mathrm{CW}$ and zirconium- 89 to monoclonal antibodies for single- or dual-mode fluorescence and PET imaging. Nat Protoc 8:1010-1018

6. Vosjan M, Perk LR, Visser GWM et al (2010) Conjugation and radiolabeling of monoclonal antibodies with zirconium-89 for PET imaging using the bifunctional chelate p-isothiocyanatobenzyldesferrioxamine. Nat Protoc 5:739-743

7. Zeglis BM, Lewis JS (2011) A practical guide to the construction of radiometallated bioconjugates for positron emission tomography. Dalton Trans 40:6168-6195

8. Agarwal P, Bertozzi CR (2015) Site-specific antibody-drug conjugates: the nexus of bioorthogonal chemistry, protein engineering, and drug development. Bioconjug Chem 26:176-192

9. Harris LJ, Skaletsky E, McPherson A (1998) Crystallographic structure of an intact IgG1 monoclonal antibody. J Mol Biol 275:861-872

10. Wang LT, Amphlett G, Blattler WA, Lambert JM, Zhang W (2005) Structural characterization of the maytansinoid-monoclonal antibody immunoconjugate, huN901-DM1, by mass spectrometry. Protein Sci 14:2436-2446

11. Dobrenkov K, Cheung N-KV (2014) GD2-targeted immunotherapy and radioimmunotherapy. Semin Oncol 41:589-612

12. Zhou Q, Stefano JE, Manning C et al (2014) Site-specific antibody-drug conjugation through glycoengineering. Bioconjug Chem 25:510-520

13. Zeglis BM, Davis CB, Aggeler R et al (2013) Enzyme-mediated methodology for the site-specific radiolabeling of antibodies based on catalyst-free click chemistry. Bioconjug Chem 24:1057-1067

14. Hallam TJ, Wold E, Wahl A, Smider VV (2015) Antibody conjugates with unnatural amino acids. Mol Pharm 12:1848-1862

15. Axup JY, Bajjuri KM, Ritland M et al (2012) Synthesis of site-specific antibody-drug conjugates using unnatural amino acids. Proc Natl Acad Sci U S A 109:16101-16106

16. Behrens CR, Liu B (2014) Methods for site-specific drug conjugation to antibodies. mAbs 6:46-53

17. Tinianow JN, Gill HS, Ogasawara A et al (2010) Site-specifically 89Zrlabeled monoclonal antibodies for ImmunoPET. Nucl Med Biol 37:289-297

18. Zeglis BM, Davis CB, Abdel-Atti D et al (2014) Chemoenzymatic strategy for the synthesis of site-specifically labeled immunoconjugates for multimodal PET and optical imaging. Bioconjug Chem 25:21232128 
19. Mindt TL, Jungi V, Wyss S et al (2008) Modification of different IgG1 antibodies via glutamine and lysine using bacterial and human tissue transglutaminase. Bioconjug Chem 19:271-278

20. Sletten EM, Bertozzi CR (2009) Bioorthogonal chemistry: fishing for selectivity in a sea of functionality. Angew Chem Int Ed 48:6973-6998

21. Waengler C, Schirrmacher R, Bartenstein P, Waengler B (2010) Clickchemistry reactions in radiopharmaceutical chemistry: fast \& easy introduction of radiolabels into biomolecules for in vivo imaging. Curr Med Chem 17:1092-1116

22. Patterson JT, Asano S, Li X, Rader C, Barbas CF (2014) Improving the serum stability of site-specific antibody conjugates with sulfone linkers. Bioconjug Chem 25:1402-1407

23. Junutula JR, Raab H, Clark S et al (2008) Site-specific conjugation of a cytotoxic drug to an antibody improves the therapeutic index. Nat Biotechnol 26:925-932

24. Pillow TH, Tien J, Parsons-Reponte KL et al (2014) Site-specific trastuzumab maytansinoid antibody-drug conjugates with improved therapeutic activity through linker and antibody engineering. J Med Chem 57:7890-7899

25. Boswell CA, Mundo EE, Zhang C et al (2011) Impact of drug conjugation on pharmacokinetics and tissue distribution of antiSTEAP1 antibody-drug conjugates in rats. Bioconjug Chem 22:19942004

26. Alvarez VL, Wen ML, Lee C, Lopes AD, Rodwell JD, McKearn TJ (1986) Site-specifically modified In-111 labeled antibodies give low liver backgrounds and improved radioimmunoscintigraphy. Nucl Med Biol 13:347-352

27. Strop P, Liu S-H, Dorywalska M et al (2013) Location matters: site of conjugation modulates stability and pharmacokinetics of antibody drug conjugates. Chem Biol 20:161-167

28. Wu AM (2014) Engineered antibodies for molecular imaging of cancer. Methods 65:139-147

29. Roovers RC, van Dongen GAMS, van Bergen en Henegouwen PMP (2007) Nanobodies in therapeutic applications. Curr Opin Mol Ther 9:327-335

30. Scott AM, Wolchok JD, Old LJ (2012) Antibody therapy of cancer. Nat Rev Cancer 12:278-287

31. Roux KH, Monafo WJ, Davie JM, Greenspan NS (1987) Construction of an extended 3-dimensional idiotope map by electron-microscopic analysis of idiotope-anti-idiotope complexes. Proc Natl Acad Sci U S A 84:4984-4988

32. Schroeder HW Jr, Cavacini L (2010) Structure and function of immunoglobulins. J Allergy Clin Immunol 125:S41-S52

33. Schroeder HW, Wald D, Greenspan NS (2013) Immunoglobulins: structure and function. Lippincott, Williams, and Williams, Philadelphia

34. Chothia C, Novotny J, Bruccoleri R, Karplus M (1985) Domain association in immunoglobulin molecules - the packing of variable domains. J Mol Biol 186:651-663

35. Kabat EA, Wu TT, Bilofsky H (1979) Evidence supporting somatic assembly of the DNA segments (minigenes) coding for the framework and complementarity-determining segments of immunoglobulin variable regions. J Exp Med 149:1299-1313

36. Arnold JN, Wormald MR, Sim RB, Rudd PM, Dwek RA (2007) The impact of glycosylation on the biological function and structure of human immunoglobulins. Annu Rev Immunol 25:21-50

37. Hayes JM, Cosgrave EF, Struwe WB (2014) Glycosylation and Fc receptors. Curr Top Microbiol Immunol 382:165-199

38. Porter RR (1950) A chemical study of rabbit antiovalbumin. Biochem J 46:473-478

39. Porter RR (1958) Separation and isolation of fractions of rabbit gammaglobulin containing the antibody and antigenic combining sites. Nature 182:670-671

40. Porter RR (1959) Hydrolysis of rabbit gamma-globulin and antibodies with crystalline papain. Biochem J 73:119-126

41. Nisonoff A, Wissler FC, Lipman LN (1960) Properties of the major component of a peptic digest of rabbit antibody. Science 132:17701771

42. Freise AC, $\mathrm{Wu}$ AM (2015) In vivo imaging with antibodies and engineered fragments. Mol Immunol 67:142-152

43. Muyldermans S (2013) Nanobodies: natural single-domain antibodies. Annu Rev Biochem 82(82):775-797

44. Ying T, Gong R, Ju TW, Prabakaran P, Dimitrov DS (2014) Engineered Fc based antibody domains and fragments as novel scaffolds. Biochim Biophys Acta-Proteins Proteomics 1844:1977-1982
45. Means GE, Feeney RE (1990) Chemical modifications of proteins: history and applications. Bioconjug Chem 1:2-12

46. Toda N, Asano S, Barbas CF (2013) Rapid, stable, chemoselective labeling of thiols with Julia-Kocieński-like reagents: a serum-stable alternative to maleimide-based protein conjugation. Angew Chem Int Ed 52:12592-12596

47. Badescu G, Bryant P, Swierkosz J et al (2014) A new reagent for stable thiol-specific conjugation. Bioconjug Chem 25:460-469

48. Sato M, Toyozaki T, Odaka K et al (2002) Detection of experimental autoimmune myocarditis in rats by 111 In monoclonal antibody specific for tenascin-C. Circulation 106:1397-1402

49. Li J, Wang X-h, Wang X-m, Z-1 C (2006) Site-specific conjugation of bifunctional chelator BAT to mouse $\mathrm{IgG} 1 \mathrm{Fab}^{\prime}$ fragment. Acta Pharmacol Sin 27:237-241

50. Slinkin MA, Curtet C, Sai-Maurel C, Gestin JF, Torchilin VP, Chatal JF (1992) Site-specific conjugation of chain-terminal chelating polymers to Fab' fragments of anti-CEA mAb: effect of linkage type and polymer size on conjugate biodistribution in nude mice bearing human colorectal carcinoma. Bioconjug Chem 3:477-483

51. Hamblett KJ, Senter PD, Chace DF et al (2004) Effects of drug loading on the antitumor activity of a monoclonal antibody drug conjugate. Clin Cancer Res 10:7063-7070

52. Qiao R, Liu C, Liu M et al (2015) Ultrasensitive in vivo detection of primary gastric tumor and lymphatic metastasis using upconversion nanoparticles. ACS Nano 9:2120-2129

53. Sun MMC, Beam KS, Cerveny CG et al (2005) Reduction-alkylation strategies for the modification of specific monoclonal antibody disulfides. Bioconjug Chem 16:1282-1290

54. Jones MW, Strickland RA, Schumacher FF et al (2012) Polymeric dibromomaleimides as extremely efficient disulfide bridging bioconjugation and PEGylation agents. J Am Chem Soc 134:18471852

55. Khalili H, Godwin A, J-w C, Lever R, Brocchini S (2012) Comparative binding of disulfide-bridged PEG-Fabs. Bioconjug Chem 23:22622277

56. Schumacher FF, Sanchania VA, Tolner B et al (2013) Homogeneous antibody fragment conjugation by disulfide bridging introduces 'spinostics'. Sci Rep 3

57. Woo HJ, Lotz MM, Jung JU, Mercurio AM (1991) Carbohydratebinding protein 35 (Mac-2), a laminin-binding lectin, forms functional dimers using cysteine 186. J Biol Chem 266:18419-18422

58. Wootton SK, Yoo D (2003) Homo-oligomerization of the porcine reproductive and respiratory syndrome virus nucleocapsid protein and the role of disulfide linkages. J Virol 77:4546-4557

59. Junutula JR, Bhakta S, Raab H et al (2008) Rapid identification of reactive cysteine residues for site-specific labeling of antibody-Fabs. J Immunol Methods 332:41-52

60. Tavare R, Wu WH, Zettlitz KA et al (2014) Enhanced immunoPET of ALCAM-positive colorectal carcinoma using site-specific (64)CuDOTA conjugation. Protein Eng Des Sel 27:317-324

61. Kobayashi N, Odaka K, Uehara T et al (2011) Toward in vivo imaging of heart disease using a radiolabeled single-chain Fv fragment targeting tenascin-C. Anal Chem 83:9123-9130

62. Massa S, Xavier C, De Vos J et al (2014) Site-specific labeling of cysteine-tagged camelid single-domain antibody-fragments for use in molecular imaging. Bioconjug Chem 25:979-988

63. Albrecht H, Denardo GL, Denardo SJ (2007) Development of antiMUC1 di-scFvs for molecular targeting of epithelial cancers, such as breast and prostate cancers. Q J Nucl Med Mol Imaging 51:304-313

64. Olafsen T, Cw C, Yazaki PJ et al (2004) Covalent disulfide-linked antiCEA diabody allows site-specific conjugation and radiolabeling for tumor targeting applications. Protein Eng Des Sel 17:21-27

65. Li L, Crow D, Turatti F et al (2011) Site-specific conjugation of monodispersed DOTA-PEGn to a thiolated diabody reveals the effect of increasing PEG size on kidney clearance and tumor uptake with improved 64-copper PET imaging. Bioconjug Chem 22:709-716

66. Sirk SJ, Olafsen T, Barat B, Bauer KB, Wu AM (2008) Site-specific, thiol-mediated conjugation of fluorescent probes to cysteine-modified diabodies targeting CD20 or HER2. Bioconjug Chem 19:2527-2534

67. Kijanka M, Warnders FJ, El Khattabi M et al (2013) Rapid optical imaging of human breast tumour xenografts using anti-HER2 VHHs site-directly conjugated to IRDye $800 \mathrm{CW}$ for image-guided surgery. Eur J Nucl Med Mol Imaging 40:1718-1729 
68. Li L, Olafsen T, Anderson A-L, Wu A, Raubitschek AA, Shively JE (2002) Reduction of kidney uptake in radiometal labeled peptide linkers conjugated to recombinant antibody fragments: site-specific conjugation of DOTA-peptides to a Cys-diabody. Bioconjug Chem 13:985-995

69. Stimmel JB, Merrill BM, Kuyper LF et al (2000) Site-specific conjugation on serine $\rightarrow$ cysteine variant monoclonal antibodies. J Biol Chem 275:30445-30450

70. Boswell CA, Marik J, Elowson MJ et al (2013) Enhanced tumor retention of a radiohalogen label for site-specific modification of antibodies. J Med Chem 56:9418-9426

71. Gill HS, Tinianow JN, Ogasawara A et al (2009) A modular platform for rapid site-specific radiolabeling of proteins with $18 \mathrm{~F}$ exemplified by quantitative positron emission tomography of human epidermal growth factor receptor 2. J Med Chem 52:5816-5825

72. O'Shannessy DJ, Dobersen MJ, Quarles RH (1984) A novel procedure for labeling immunoglobulins by conjugation to oligosaccharide moieties. Immunol Lett 8:273-277

73. Panowski S, Bhakta S, Raab H, Polakis P, Junutula JR (2014) Sitespecific antibody drug conjugates for cancer therapy. mAbs 6:34-45

74. Hu MD, Chen P, Wang J, Chan C, Scollard DA, Reilly RM (2006) Sitespecific conjugation of HIV-1 tat peptides to IgG: a potential route to construct radioimmunoconjugates for targeting intracellular and nuclear epitopes in cancer. Eur J Nucl Med Mol Imaging 33:301-310

75. Wang W, Vlasak J, Li Y et al (2011) Impact of methionine oxidation in human $\mathrm{IgG1} \mathrm{Fc}$ on serum half-life of monoclonal antibodies. Mol Immunol 48:860-866

76. Rodwell JD, Alvarez VL, Chyi L et al (1986) Site-specific covalent modification of monoclonal antibodies: in vitro and in vivo evaluations. Proc Natl Acad Sci U S A 83:2632-2636

77. Lopes AD, Davis WL, Rosenstraus MJ, Uveges AJ, Gilman SC (1990) Immunohistochemical and pharmacokinetic characterization of the sitespecific immunoconjugate CYT-356 derived from antiprostate monoclonal antibody 7E11-C5. Cancer Res 50:6423-6429

78. Rosenstraus MJ, Davis WL, Lopes AD, Daleo CJ, Gilman SC (1990) Carbohydrate-derivatized immunoconjugate of the anticarcinoembryonic antigen monoclonal antibody C46: immunohistochemical reactivity and pharmacokinetic comparison with a randomly derivatized C46 immunoconjugate. Cancer Immunol Immunother 32:207-213

79. Rosenstraus MJ, Davis WL, Lopes AD, Daleo CJ, Gilman SC (1991) Immunohistochemical and pharmacokinetic characterization of sitespecific immunoconjugate $15 \mathrm{~A} 8$-glycyl-tyrosyl-(N-epsilondiethylenetriamine pentaacetic acid)-lysine derived from anti-breast carcinoma monoclonal antibody 15A8. Cancer Res 51:5744-5751

80. Maguire RT, Pascucci VL, Maroli AN, Gulfo JV (1993) Immunoscintigraphy in patients with colorectal, ovarian, and prostate cancer: results with site-specific immunoconjugates. Cancer 72:34533462

81. Benedetto S, Pulito R, Crich SG et al (2006) Quantification of the expression level of integrin receptor alpha(V)beta(3) in cell lines and MR imaging with antibody-coated iron oxide particles. Magn Reson Med 56:711-716

82. Chengazi VU, Feneley MR, Ellison D et al (1997) Imaging prostate cancer with technetium-99m-7E11-C5.3 (CYT-351). J Nucl Med $38: 675-682$
83. Stalteri MA, Mather SJ, Belinka BA, Coughlin DJ, Chengazi VU, Britton KE (1997) Site-specific conjugation and labelling of prostate antibody 7E11C5.3 (CYT-351) with technetium-99m. Eur J Nucl Med 24:651-654

84. Zuberbühler K, Casi G, Bernardes GJL, Neri D (2012) Fucose-specific conjugation of hydrazide derivatives to a vascular-targeting monoclonal antibody in $\mathrm{IgG}$ format. Chem Commun 48:7100-7102

85. Jeong JM, Lee J, Paik CH et al (2004) Site-specific Tc-99m-labeling of antibody using dihydrazinophthalazine (DHZ) conjugation to $\mathrm{Fc}$ region of heavy chain. Arch Pharmacal Res 27:961-967

86. Lu Y, Mbong GNN, Liu P et al (2014) Synthesis of polyglutamidebased metal-chelating polymers and their site-specific conjugation to trastuzumab for Auger electron radioimmunotherapy. Biomacromolecules 15:2027-2037

87. Ngo Ndjock Mbong G, Lu Y, Chan C et al (2015) Trastuzumab labeled to high specific activity with $111 \mathrm{In}$ by site-specific conjugation to a metal-chelating polymer exhibits amplified Auger electron-mediated cytotoxicity on HER2-positive breast cancer cells. Mol Pharm 12:19511960

88. Kalia J, Raines RT (2008) Hydrolytic stability of hydrazones and oximes. Angew Chem Int Ed 47:7523-7526

89. Kurth M, Pelegrin A, Rose K et al (1993) Site-specific conjugation of a radioiodinated phenethylamine derivative to a monoclonal antibody results in increased radioactivity localization in tumor. J Med Chem $36: 1255-1261$

90. Bejot R, Goggi J, Moonshi SS, Padmanabhan P, Bhakoo KK (2012) Aminooxy-functionalized DOTA for radiolabeling of oxidized antibodies: evaluation of site-specific In-111-labeled trastuzumab. J Label Compd Radiopharm 55:346-353

91. Ramakrishnan B, Qasba PK (2002) Structure-based design of beta 1,4galactosyltransferase I (beta 4GaI-T1) with equally efficient $\mathrm{N}$ acetylgalactosaminyltransferase activity - point mutation broadens beta 4GaI-T1 donor specificity. J Biol Chem 277:20833-20839

92. Boeggeman E, Ramakrishnan B, Pasek M et al (2009) Site specific conjugation of fluoroprobes to the remodeled $\mathrm{Fc} \mathrm{N}$-glycans of monoclonal antibodies using mutant glycosyltransferases: application for cell surface antigen detection. Bioconjug Chem 20:12281236

93. Khidekel N, Arndt S, Lamarre-Vincent N et al (2003) Chemoenzymatic approach toward the rapid and sensitive detection of O-GlcNAc posttranslational modifications. J Am Chem Soc 125:16162-16163

94. Li X, Fang T, Boons G-J (2014) Preparation of well-defined antibodydrug conjugates through glycan remodeling and strain-promoted azidealkyne cycloadditions. Angew Chem Int Ed 53:7179-7182

95. Rochefort MM, Girgis MD, Ankeny JS, Tomlinson JS (2014) Metabolic exploitation of the sialic acid biosynthetic pathway to generate site-specifically labeled antibodies. Glycobiology 24:62-69

96. Okeley NM, Alley SC, Anderson ME et al (2013) Development of orally active inhibitors of protein and cellular fucosylation. Proc Natl Acad Sci U S A 110:5404-5409

97. Okeley NM, Toki BE, Zhang X et al (2013) Metabolic engineering of monoclonal antibody carbohydrates for antibody-drug conjugation. Bioconjug Chem 24:1650-1655 